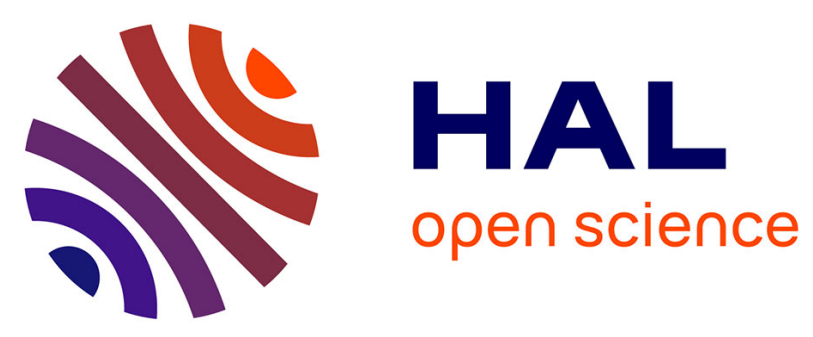

\title{
Stability and degradation of PEO20PPO70PEO20 triblock copolymers in mesostructured silica
}

Brindusa Dragoi, Guillaume Laurent, Sandra Casale, Taissire Benamor, Bénédicte Lebeau, Cédric Boissière, François Ribot, Mohamed Selmane, Patrick Schmidt, David Kreher, et al.

\section{To cite this version:}

Brindusa Dragoi, Guillaume Laurent, Sandra Casale, Taissire Benamor, Bénédicte Lebeau, et al.. Stability and degradation of PEO20PPO70PEO20 triblock copolymers in mesostructured silica. Journal of Sol-Gel Science and Technology, 2019, 91 (3), pp.552-566. 10.1007/s10971-019-05044-w . hal02175149

\section{HAL Id: hal-02175149 \\ https://hal.sorbonne-universite.fr/hal-02175149}

Submitted on 5 Jul 2019

HAL is a multi-disciplinary open access archive for the deposit and dissemination of scientific research documents, whether they are published or not. The documents may come from teaching and research institutions in France or abroad, or from public or private research centers.
L'archive ouverte pluridisciplinaire HAL, est destinée au dépôt et à la diffusion de documents scientifiques de niveau recherche, publiés ou non, émanant des établissements d'enseignement et de recherche français ou étrangers, des laboratoires publics ou privés. 


\title{
Stability and degradation of $\mathrm{PEO}_{20} \mathrm{PPO}_{70} \mathrm{PEO}_{20}$ triblock copolymers, in mesostructured silica
}

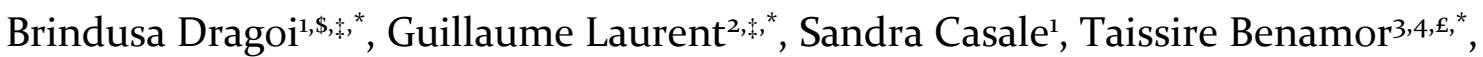 \\ Bénédicte Lebeau ${ }^{3,4}$, Cédric Boissière ${ }^{2}$, François Ribot ${ }^{2}$, Mohamed Selmane5, \\ Patrick Schmidt ${ }^{6}$, David Kreher ${ }^{7}$, Anne Davidson ${ }^{1, \$}$
}

\author{
${ }^{1}$ Sorbonne Université, CNRS, Laboratoire de Réactivité de Surface, 4 Place Jussieu, F75005 Paris, France \\ ${ }^{2}$ Sorbonne Université, CNRS, Laboratoire de Chimie de la Matière Condensée de Paris, 4 place Jussieu, F75005 Paris, \\ France \\ ${ }^{3}$ Université de Haute Alsace, CNRS, Institut de Science des Matériaux de Mulhouse, 3bis rue A. Werner, F68100 Mulhouse, \\ France \\ ${ }^{4}$ Université de Strasbourg, France \\ ${ }^{5}$ Sorbonne Université, CNRS, Institut des Matériaux de Paris Centre, 4 place Jussieu, F75005 Paris, France \\ ${ }^{6}$ Eberhard Karls University of Tübingen, Department of Geosciences, Applied Mineralogy, Wilhelmstraße 56, 72074 Tü- \\ bingen, Germany \\ ${ }^{7}$ Sorbonne Université, CNRS, Laboratoire de Chimie des Polymères, 4 Place Jussieu, F75005 Paris, France
}

${ }^{\$}$ Current address: Alexandru Ioan Cuza University of Iasi, $11^{\text {th }}$ Carol I Boulevard, 700506 Iasi, Romania

${ }^{£}$ Current address: Technopole de Borj-Cédria, Centre de Recherches et des Technologies des Eaux, Route touristique de Soliman, BP 273-8020 Soliman, Tunisia

$\$$ These authors contributed equally

*Corresponding authors

KEYWORDS: NMR, NIR, $P_{123}$, template, ordered, structured

SECTION/CATEGORY: Nano-structured materials (particles, fibers, colloids, composites, etc..) 


\section{Highlight}

- Mesostructured "hybrids" containing silica and $\mathrm{P}_{123}$ triblock copolymers obtained by precipitation (in acidic $\mathrm{HCl}$ solution) and spray drying are compared

- A copolymer acidic hydrolysis is observed for all samples having been heated during synthesis (that is, hydrothermal treatment for synthesis by precipitation, or drying temperature for spray drying experiments).

- 1,2-ethanediol and peroxide traces associated with the copolymer oxidative decomposition are identified by NMR.

- The temperature of the heat treatment applied for HT is directly correlated with the remaining EO/ $(\mathrm{EO}+\mathrm{PO})$ weight $\%$.

- The NMR study of polymer chains mobility confirms the dehydration and retraction of hydrated PEO chains from silica walls upon temperature increase.

- We proved for the first time that this effect, now well known for precipitated SBA-15 materials, also occur for spray-dried samples. 


\section{GRAPHCAL ABSTRACT}

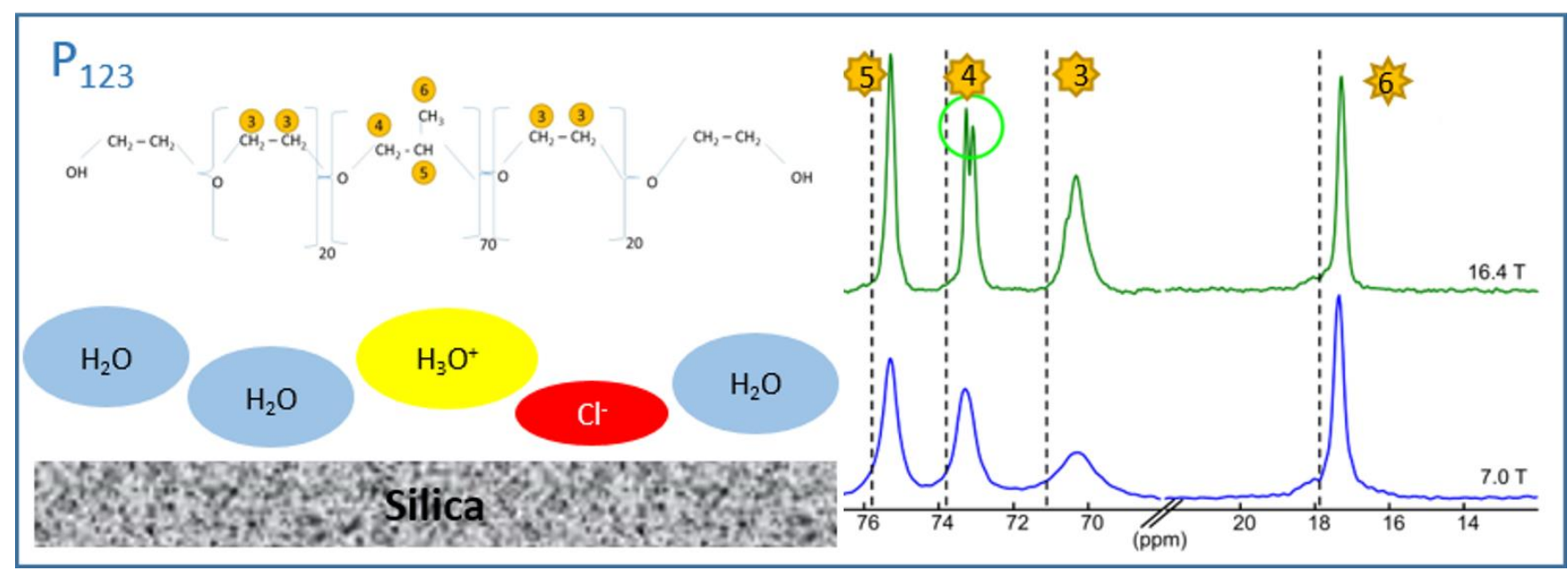


ABSTRACT: Organic-inorganic hybrid mesostructured silicas are prepared, without stirring (at $\mathrm{pH} 0.0$ ) and with stirring (at $\mathrm{pH}$ 0.6) to obtain isolated and gyroidal-like attached silica grains with incorporated triblock $\mathrm{P}_{123}$ poly (ethylene oxide)-poly (propylene oxide)-poly (ethylene oxide) copolymers. Selected hybrids are submitted to various thermal and aging treatments for studying hydrolysis and oxidation of PEO and PPO chains. Two complementary spectroscopic techniques are used. NearInfrared (NIR) with measurements performed in diffuse reflectance as well as ${ }^{1} \mathrm{H}$ and ${ }^{13} \mathrm{C}$ liquid- and solid-state Nuclear Magnetic Resonance (NMR) to study mobility and stability of PEO and PPO chains. With precipitated fresh hybrids, the ratio of $\mathrm{PEO}$ over $(\mathrm{PEO}+\mathrm{PPO})$ units is lower $(\% 30 \pm 5 \%)$ than in theory. This ratio also decreases depending on temperature when a hydrothermal treatment is applied. An acidic hydrolysis involving both PEO and PPO chains, with generated fragments eliminated by washing with water and/or synthesis liquor, is then demonstrated. For comparison, another hybrid obtained by spray drying via Evaporation Induced Self Assembly mechanism, is also studied. Its NMR signals are much more stable than those of the samples prepared by precipitation. Depending on aging time, thermal history and materials processing, the textural properties and template decomposition inside mesostructured silica are found significantly different. The influence of the hydrolysis and oxidation of the template onto final materials texture is likely to be as important as processing conditions.

\section{Introduction}

Applications of pharmaceutical molecules, anti-inflammatory drugs for instance that are generally large organic molecules of poor hydrophilic character and are poorly soluble in natural fluids containing a lot of water, is an important and very actual challenge [1]. Ordered mesoporous silicas (OMS) which are synthesized with organic templates, are chemically inert, biocompatible, easy to functionalize, and are perfect carriers for these molecules. The OMS are synthetized by auto-organization between organic templates and silica precursors [2-3]. As made hybrids can be formed by precipitation at acidic $\mathrm{pH}$ with triblock copolymers as templates, in particular the ones that are formed by two poly (ethylene oxide) chains, PEO, surrounding a central hydrophobic poly (propylene oxide) PPO chain. $\mathrm{PEO}_{20} \mathrm{PPO}_{70} \mathrm{PEO}_{20}$, also called $\mathrm{P}_{123}$ is popular and commercialized by BASF, ICI and Aldrich. With this peculiar copolymer, in situ observations, starting from the very beginning of the hybrid preparation when an organic/inorganic mixture is prepared in an acidic aqueous solution, are now available. Results from Transmission Electron Microscopy recorded at cryogenic temperature (cryo-TEM) [4] on hybrid powders dispersed in water and iced and of time-resolved Small Angle X-ray Scattering studies (SAXS) [5] allowed to discriminate several steps in the OMS formation : i) first, the formation of spherical organic micelles, ii) secondly, aqueous silicate anions are adsorbed and condense on organic micelles. The spherical micelles are elongating, iii) a bi-dimensional hexagonal structure forming a floc but remaining "soft", forming a silicate-surfactant "liquid crystal", similar to that observed when cationic surfactants and silicates anions are mixed to form MCM-type silica at $\mathrm{pH}=6[6]$ is formed, iv) a condensation-polymerization of silicate anions to form silica walls, v) organics removal and pores liberation. Several methods to remove the template have been tested such as a stepwise washing with $\mathrm{H}_{2} \mathrm{SO}_{4}$ then calcination [7] or washings with ethanol [8] and a complete calcination [9]. Recent detailed SAXS, and Small Angle Neutron Scattering studies (SANS) have been devoted to kinetical aspects of the auto-organization between water, organics, and inorganic precursors [10-11]. Specific information about the formation of isolated silica grains has also been reported [12]. Despite all available information, the reported techniques of synthesis remain complex to use in terms of scalability and reproducibility in the final texture of silica grains, and this nicely explains why in addition to classical precipitation methods, other methods of preparation, such as evaporation Induced Self Assembly by spray drying have been developed by several groups [13-15]. On materials prepared by EISA, the order of mesopores inside silica has been 
studied by SAXS and a study about the aggregation of mesostructured titanium oxide nanoparticles has also been reported [14]. This approach was enlarged to many other organized mesoporous metal oxides [15, 16].

The goal of the present work is to compare the conformation and mobility of the organic template within various silica-based mesostructured obtained by precipitation in different conditions to a similar hybrid obtained by EISA. For the two modes of synthesis, we have used the triblock copolymer $\mathrm{P}_{123}$ because it is nowadays one of the most popular copolymer used as a template, a molecular Tetraethyl Orthosilicate, TEOS, and $\mathrm{HCl}$ aqueous solutions. Experimental conditions, in particular $\mathrm{P}_{123}$ and Si precursors molar ratios, are close to those initially described [12]. Differences are associated with experimental details, such as stirring rates and time, $\mathrm{pH}$ from 0.3-0.6 to 1.8-2 and post-synthesis treatment conditions (drying, calcination, and storage time in air). Experimental data described to obtain a few grams of hybrid powder are extrapolated for the preparation of more than $50 \mathrm{~g}$ of hybrid. Despite precautions and the use of strong washing conditions (with at least the equivalent of $3 \mathrm{~L}$ of water to wash $50 \mathrm{~g}$ of silica), a chloride contamination is difficult to avoid. Spectroscopic information concerning water and its interaction with organic groups is described first by Near-Infrared (NIR) spectroscopy and then by ${ }^{1} \mathrm{H}$ and ${ }^{13} \mathrm{C}$ liquid- and solid-state Nuclear Magnetic Resonance (NMR) spectroscopy. The copolymers, their chemical composition and their conformation are first described in diluted solutions and then within hydrated hybrids. Described results concern uncalcined samples. Although organic compounds trapped within silica are often described are more stable than their unconfined counterpart, a polymer acidic hydrolysis is detected and quantified. It was important to establish if this hydrolysis was related with practical modifications of porosity of the final material, observed after the removal of the copolymer by calcination in air. Surprisingly, we observed that dry hybrid powders mesostructure was affected by long term storage, highlighting that if any mass production of such material is envisioned, a serious stability issue of the product is to expect.

\section{Materials and methods}

\section{II.1. Reagents}

Tetraethoxysilane (reagent grade, $98 \%$ ), the surfactant $\mathrm{P}_{123}$ of molecular weight 5800 g.mol ${ }^{-1}$ and formula $\mathrm{CH}_{3}-\left(\mathrm{CH}_{2}-\mathrm{CH}_{2}-\right.$ $\mathrm{O})_{20}-\left(\mathrm{CH}_{3}-\mathrm{CH}-\mathrm{CH}_{2}-\mathrm{O}\right)_{70}-\left(\mathrm{CH}_{2}-\mathrm{CH}_{2}-\mathrm{O}\right)_{20}-\mathrm{H}$ and an NMR standard adamantane (solid) were provided by Sigma Aldrich and were used as received. Another solvent, dimethylformamide (DMF) of chromatographic grade was also obtained from Sigma Aldrich. $\mathrm{HCl}$ was an ACS grade Carlo Erba, at 37 or $35 \%$ in volume. The $\mathrm{LiCl}$ salt was provided by Molecular Biology, Sigma and the solvent $\mathrm{C}_{6} \mathrm{D}_{6}$ by Eurisotop.

In academic research, it is common to work with copolymers as received from the manufacturer. However, the chemistry of commercial triblock copolymers can be complex in water and it has been demonstrated in 1997 that $\mathrm{PEO}_{102} \mathrm{PPO}_{39} \mathrm{PEO}_{102}$, labelled $\mathrm{F}_{88}$, and commercialized by ICI, was containing defects of polymerization, i.e., free PEO chains [16]. We have checked if similar chains can be detected with the standard $\mathrm{P}_{123}$ commercialized by Sigma Aldrich and stored in air a long time (13 months) by gel chromatography. This technique requires a polar organic solvent and we have used $\mathrm{N}$, N-dimethylformamide (DMF) containing diluted lithium chloride $\left(1 \mathrm{~g} . \mathrm{L}^{-1}\right)$. We have also checked in parallel if the same information can be obtained in a less polar $\mathrm{C}_{6} \mathrm{D}_{6}$ solvent and by ${ }^{13} \mathrm{C}$ NMR with a simple $300 \mathrm{MHz}$ spectrometer.

The Center of Microanalysis, Laboratory of Solaize (France) has made the chlorine quantifications for some selected solids.

\section{II.2. Preparation of fresh hybrids}

Several precipitated hybrids, symbolized by A to E symbols, have been prepared in $\mathrm{HCl}$ aqueous solutions, then dried in air and further investigated without calcination. 
A to D hybrids correspond to a TEOS over $\mathrm{P}_{123}$ molar ratio of $60.0-62.5$, to a volume of $167.5 \pm 2.5 \mathrm{~mL}$ of TEOS and to a weight of $72 \pm 0.5 \mathrm{~g}$ of $\mathrm{P}_{123}$. Only the A sample, obtained in $\mathrm{HCl} 1.9$ mol. $\mathrm{L}^{-1}$, was kept unwashed and has been directly dried in air. All the other samples have been prepared B: $\mathrm{HCl} 1.6$ or C, D: 0.3 mol.L-1, washed, with 1, 2, 3 or $6 \mathrm{~L}$ of distilled water for $50 \mathrm{~g}$ of solid.

Two other samples, called E_HT90_U and E_HT100_U were synthesized in $\mathrm{HCl} 0.6 \mathrm{~mol} . \mathrm{L}^{-1}$ with a first aging at $28^{\circ} \mathrm{C}$ for $48 \mathrm{~h}$ followed by a hydrothermal treatment at $90^{\circ} \mathrm{C}$ of $24 \mathrm{~h}$ or $100^{\circ} \mathrm{C}$ for $48 \mathrm{~h}$, in a $500 \mathrm{~mL}$ Nalgene ${ }^{\circledR}$ flask. The powder was recovered by filtration then washed with distilled water and dried at $70^{\circ} \mathrm{C}$ in air. A constant stirring was kept during the aging step, to obtain specifically attached silica grains forming a double gyroidal structure. A last F sample was obtained by EISA. A solution made prepared with $\mathrm{P}_{123} /$ TEOS/Water $(\mathrm{pH}=2)$ of molar ratio 0.01/1/53 was spray-dried after 30 min of prehydrolysis using a Buchi B290 (liquid feeding rate 5mL.min ${ }^{-1}$ ) and submitted to air drying at temperature of $220^{\circ} \mathrm{C}$ for $2.5 \mathrm{~s}$. All the experimental conditions are summarized in Table 1 and additional information is given in Supplementary Information.

Table 1. Experimental conditions of synthesis for uncalcined (U) and calcined silicas $\left(\mathrm{C}\right.$, at $500^{\circ} \mathrm{C}$ at a rate of $2^{\circ} \mathrm{C}$ by min, then maintained $6 \mathrm{~h}$, in air)

\begin{tabular}{|c|c|c|c|c|c|c|c|}
\hline Label & $\begin{array}{l}P_{123} \\
(g)\end{array}$ & $\begin{array}{c}\text { TEOS } \\
(\mathrm{g})\end{array}$ & $\begin{array}{c}\mathrm{HCl} \\
(37 \mathrm{wt} \%) \\
(\mathrm{g})\end{array}$ & $\begin{array}{l}\text { Distilled } \\
\text { water } \\
(\mathrm{g})\end{array}$ & $\begin{array}{l}{[\mathrm{HCl}] \text { in }} \\
\text { synthesis } \\
\left(\text { mol. }^{-1}\right)\end{array}$ & $\begin{array}{c}\text { Aging } \\
\text { Temperature }\left({ }^{\circ} \mathrm{C}\right) \\
\text { time }(\mathrm{h})\end{array}$ & $\begin{array}{c}\text { Applied } \\
\text { treatments be- } \\
\text { fore calcination }\end{array}$ \\
\hline A_U & \multirow[t]{3}{*}{72.7} & \multirow[t]{3}{*}{158.1} & \multirow[t]{3}{*}{318.2} & \multirow[t]{3}{*}{1832.00} & \multirow[t]{3}{*}{1.9} & \multirow[t]{3}{*}{$35^{\circ} \mathrm{C} 24 \mathrm{~h}$} & $\begin{array}{c}\text { No HT } \\
\text { Filtration, dry- } \\
\text { ing in air }\end{array}$ \\
\hline A_HT95_U & & & & & & & $\mathrm{HT} 95^{\circ} \mathrm{C} 24 \mathrm{~h}$ \\
\hline A_HT130_U & & & & & & & $\mathrm{HT} 130^{\circ} \mathrm{C} 24 \mathrm{~h}$ \\
\hline B_U & \multirow[t]{3}{*}{71.6} & \multirow[t]{3}{*}{155.6} & \multirow[t]{3}{*}{287.0} & \multirow[t]{3}{*}{1863.0} & \multirow[t]{3}{*}{1.6} & \multirow[t]{3}{*}{$35^{\circ} \mathrm{C}, 24 \mathrm{~h}$} & $\begin{array}{c}\text { No HT } \\
\text { Filtration, } \\
\text { Washing, Dry- } \\
\text { ing in air }\end{array}$ \\
\hline B_dried_ $70^{\circ} \mathrm{C}$ & & & & & & & $\begin{array}{l}\text { No } \mathrm{HT} \text {, dried at } \\
70^{\circ} \mathrm{C} \text { in air } 26 \mathrm{~h}\end{array}$ \\
\hline B_HT130_U & & & & & & & $\mathrm{HT} 130^{\circ} \mathrm{C} 24 \mathrm{~h}$ \\
\hline $\mathrm{C}_{-} \mathrm{U}$ & \multirow[t]{2}{*}{71.6} & \multirow[t]{2}{*}{155.6} & \multirow[t]{2}{*}{54.0} & \multirow[t]{2}{*}{2096.0} & \multirow[t]{2}{*}{0.3} & \multirow[t]{2}{*}{$35^{\circ} \mathrm{C}, 24 \mathrm{~h}$} & No HT \\
\hline C_HT130_U & & & & & & & $\mathrm{HT} 130^{\circ} \mathrm{C} 24 \mathrm{~h}$ \\
\hline D_U & \multirow[t]{2}{*}{71.6} & \multirow[t]{2}{*}{155.6} & \multirow[t]{2}{*}{33.9} & \multirow[t]{2}{*}{1321.0} & \multirow[t]{2}{*}{0.3} & \multirow[t]{2}{*}{$35^{\circ} \mathrm{C}, 24 \mathrm{~h}$} & No HT \\
\hline D_HT130_U & & & & & & & HT $130^{\circ} \mathrm{C} 24 \mathrm{~h}$ \\
\hline E_HT90_U & 13.9 & 26.7 & 23.6 & 130.0 & & & $\begin{array}{l}\mathrm{HT} 90^{\circ} \mathrm{C}, 24 \mathrm{~h} \\
\text { dried } 70^{\circ} \mathrm{C}\end{array}$ \\
\hline E_HT100_U & & & & & & & $\begin{array}{c}\mathrm{HT}^{*} 100^{\circ} \mathrm{C}, 48 \\
\mathrm{~h} \\
\text { dried } 70^{\circ} \mathrm{C}\end{array}$ \\
\hline F_U & 12.4 & 41.5 & 0.3 & 193.0 & $10^{-2}$ & $220^{\circ} \mathrm{C}, 2.5 \mathrm{~s}$ & $\begin{array}{l}\text { Used fresh or } \\
\text { after calcina- } \\
\text { tion at } 130, \\
350 \text { and at } \\
550^{\circ} \mathrm{C} \text { in air } \\
\left(2^{\circ} \mathrm{C} \text { by min }\right)\end{array}$ \\
\hline $\begin{array}{l}\text { All solids recc } \\
\text { HT: hydrother } \\
\text { in Nalgene fla }\end{array}$ & & ation & bre and aft & $\begin{array}{l}\text { ed with } \\
\text { nen let }\end{array}$ & uival & $3 \mathrm{~L}$ distilled wat & $\begin{array}{l}\text { r } 50 \mathrm{~g} \text { of solid } \\
\text { d } 0.5 \text { L or HT* } \\
\text { lled jacket be- }\end{array}$ \\
\hline
\end{tabular}




\section{II.3. Stabilization and calcination conditions}

Fraction of the B_U sample (washed, lower chlorine contamination) was submitted to a heat treatment at $70^{\circ} \mathrm{C}$ in air for $26 \mathrm{~h}$ in a muffle oven, to obtain the B_dried70_U. This treatment aimed at simplifying the comparison with the sample called E_HT90_dried70_U.

Calcination was performed in air at $500^{\circ} \mathrm{C}\left(\right.$ rate of $2^{\circ} \mathrm{C} \mathrm{min}^{-1}$ ) for $6 \mathrm{~h}$. Calcined samples were labelled by replacing the $\mathrm{U}$ symbol with the symbol C for calcined. E_HT90_dried70_U was filtered and its heat treatment was performed in air at $550^{\circ} \mathrm{C}$ for $6 \mathrm{~h}$ with a heating rate of $1.5^{\circ} \mathrm{C} \cdot \mathrm{min}^{-1}$. The $\mathrm{F}_{-} \mathrm{U}$ sample, prepared by EISA at $220^{\circ} \mathrm{C}$ for $2.5 \mathrm{~s}$, was used fresh and/or further treated in air, at three distinct temperatures, 130,350 and $550^{\circ} \mathrm{C}$. A given sample A_U, in which some decomposition of $\mathrm{P}_{123}$ chains was suggested by preliminary NMR experiments, was submitted after one year of storage to washing (with ethanol and $\left.\mathrm{D}_{2} \mathrm{O}\right)$ to recover organic fragments. The powder was suspended in ethanol $(200 \mathrm{mg}$ in $100 \mathrm{~mL})$ and extracted at $60^{\circ} \mathrm{C}$ for $5 \mathrm{~h}$ in a $100 \mathrm{~mL}$ round bottom flask. The solution was then cooled down and the solid recovered by centrifugation. Ethanol was reintroduced inside the flask and allowed for complete dryness preferablyby means of a rotary evaporator and under primary vacuum. The non-evaporated fraction remaining on the flask walls was then recovered with $10 \mathrm{~mL}$ of $\mathrm{C}_{6} \mathrm{D}_{6}$ (less polar) or $\mathrm{D}_{2} \mathrm{O}$ (polar).

\section{II.4. Methods}

Size exclusion chromatography used to discriminate polymers fragments and spectroscopic methods (NIR, liquid- and solidstate NMR) are described here. The other techniques, necessary to investigate the texture of calcined grains, are summarized in Supplementary Information.

\section{II.4.1. Chromatographic measurements}

A dilution of copolymer in DMF containing dissolved Lithium Bromide $\mathrm{LiBr}(2 \mathrm{wt} \%)$ has been characterized by size exclusion chromatography at $60^{\circ} \mathrm{C}$, with a flow rate of $0.8 \mathrm{~mL} \cdot \mathrm{min}^{-1}$ and for a concentration of $6 \mathrm{mg}$. $\mathrm{L}^{-1}$, after filtration through a cellulose membrane $(0.2 \mu \mathrm{m}$ pore size). The steric exclusion was carried out by chromatography with one PSS GRAM $30 \AA$ column (300 mm long; separation limits: 0.1 to $10 \mathrm{~kg} \cdot \mathrm{mol}^{-1}$ ) coupled with a differential refractive index (RI) fluorescence detector (SPECTRO, Ametek), a viscosimeter detector (Viscotek, Dual 250) and a light scattering (LS) detector (MiniDawn from Wyatt Technology, laser $\lambda=690 \mathrm{~nm}$ ). The average molar masses, M, were derived from a universal calibration curve, obtained with $\eta$ viscosity and representing $\log (\eta * M)$, as a function of the elution volume based on polystyrene standards from Polymer Standards Service (limits: $100-2 * 10^{6} \mathrm{~g} \cdot \mathrm{mol}^{-1}$ ), using the OmniSEC 4.6 software.

\section{II.4.2. NIR spectroscopy}

NIR spectra collected on calcined samples and used to quantify water, as well as silanols groups are described in Supplementary Information, part S. I. 4. The NIR spectra described in the main text were recorded on selected uncalcined U hybrids. A Varian 5000 spectrometer was used. Spectra in the NIR (2500 - $800 \mathrm{~nm})$, visible $(800-400 \mathrm{~nm})$, and UV (400 - $200 \mathrm{~nm})$ spectral ranges were directly acquired with an internal sphere accessory, covered with Teflon and then in the Diffuse Reflectance mode (DR). To enhance the resolution of spectra, the second derivative spectra were calculated with the software available on the spectrometer as recommended for water containing silica samples. Spectra were collected with a resolution of $2 \mathrm{~nm}$ and with a rate of 600 or $200 \mathrm{~nm} \cdot \mathrm{min}^{-1}$. The bands analyzed in the NIR spectra are caused by the combination modes and overtones of the fundamental vibrations of stretching and elongation that can be detected in the IR-range. The positions of the peaks and the proposed attributions are consistent with current literature [17-25]. The identifications are consistent for instance, with 
those proposed for liquid oleic acids diluted in water, as recently acquired with a 2D-correlation spectroscopic method [19], in which the peaks observed in the IR and NIR-ranges were correlated. As references, we have also collected the NIR spectra of several copolymers corresponding to molar PEO wt. $\%$ of 16 and $12 \%\left(\mathrm{~F}_{127}, \mathrm{PEO}_{127} \mathrm{PPO}_{70} \mathrm{PEO}_{127}\right.$ and $\mathrm{F}_{88}$, $\mathrm{PEO}_{102} \mathrm{PPO}_{39} \mathrm{PEO}_{102}$ ) and to a polyethylene glycol polymer (PEG 1500, polyethylene oxide groups only). References 22 to 26 specifically concern NIR of water spectra collected on acidic aqueous solutions [21] and in mineral solids (chalcedony [22, 23], silica [24] and opals [25]).

\section{II.4.3. Liquid-state NMR}

${ }^{1} \mathrm{H}$ and ${ }^{13} \mathrm{C}$ spectra were measured at room temperature on a Bruker spectrometer operating at $300 \mathrm{MHz}$ for ${ }^{1} \mathrm{H}$ and $75 \mathrm{MHz}$ for ${ }^{13} \mathrm{C}$ atoms, with a BBFO-5 mm probe equipped with z-gradients.

Heteronuclear Single Quantum Coherence, H. S. Q. C. $\left\{{ }^{13} \mathrm{C}\right\}-{ }^{1} \mathrm{H}$ short range correlation and Heteronuclear Multiple Bond Correlation, H. M. B. C. ${ }^{13} \mathrm{C}-{ }^{1} \mathrm{H}$ long range correlation was obtained with 1 and 2 scans, respectively, a relaxation delay of $1 \mathrm{~s}$ and 256 slices. Spectra were calibrated to $\mathrm{C}_{6} \mathrm{D}_{6}$ solvent peaks, set at 7.16 and $128.06 \mathrm{ppm}$ for ${ }^{1} \mathrm{H}$ and ${ }^{13} \mathrm{C}$, respectively, and relative to tetramethylsilane (1\% TMS in $\mathrm{CDCl}_{3}$, set at zero [26]).

\section{II.4.4. Solid-state NMR}

First experiments were conducted on a Bruker Advance III $7 \mathrm{~T}$ spectrometer operating at $300 \mathrm{MHz}$ for ${ }^{1} \mathrm{H}$ and $75 \mathrm{MHz}$ for ${ }^{13} \mathrm{C}$ and equipped with a $7 \mathrm{~mm}$ Magic Angle Spinning (MAS) double resonance broad band probe (MAS rate $5 \mathrm{kHz}$ ). Following experiments were conducted on a Bruker Advance III spectrometer operating at $700 \mathrm{MHz}$ for ${ }^{1} \mathrm{H}$ and $175 \mathrm{MHz}$ for ${ }^{13} \mathrm{C}$. A 3.2 mm MAS tri-gamma broadband probe (MAS rate $20 \mathrm{kHz}$ ) and a $1.3 \mathrm{~mm}$ MAS double-resonance broadband probe (MAS rate $40 \mathrm{kHz}$ ) were used. All experiments were done with $\mathrm{ZrO}_{2}$ rotors. Chemical shifts of ${ }^{1} \mathrm{H}$ and ${ }^{13} \mathrm{C}$ nuclei were calibrated using solid adamantane $\left(\mathrm{C}_{10} \mathrm{H}_{16}\right)$ signals at 1.85 and $37.77 \mathrm{ppm}$, respectively relative to tetramethylsilane [27]. To correct the observed frequency shifts and increase the precision on chemical shifts, calibration was applied before each series of spectral acquisitions.

${ }^{13} \mathrm{C}$ and ${ }^{1} \mathrm{H}$ solid-state NMR spectra were obtained by several sequences, including high power decoupling, HPDEC, to remove efficiently ${ }^{13} \mathrm{C}-{ }^{1} \mathrm{H}$ heteronuclear dipolar interactions, Insensitive Nuclei Enhanced by Polarization Transfer, INEPT, and Cross Polarization, CP. The INEPT sequence is recognized as particularly efficient to discriminate ${ }^{13} \mathrm{C}$ atoms in mobile organic species. Negative signals are associated with $-\mathrm{CH}_{2}-$ (secondary) groups whereas positive signals are recorded for methyl $\mathrm{CH}_{3}$ (primary) and - $\mathrm{CH}-$ (ternary) groups [28-29]. Quaternary carbons are not detected. Spectra obtained with cross-polarization (CP) sequence help to detect the poorly mobile species. Additionally, a $2 \mathrm{D}$ heteronuclear $\left\{{ }^{1} \mathrm{H}\right\}-{ }^{13} \mathrm{C}$ INEPT spectrum has also been acquired to evidence the hydrolysis of $\mathrm{P}_{123}$ fragments and to demonstrate that they do not interact with remaining $\mathrm{P}_{123}$ molecules. The used parameters are displayed in each figure captions: magnetic field strength $\left(\mathrm{B}_{0}\right)$, Recycle Delay (RD), Number of Scans (NS), Line Broadening (LB), MAS rate $\left(v_{\mathrm{r}}\right)$, and CP contact time $\left(\mathrm{t}_{\mathrm{cp}}\right)$.

\section{Results and discussion}

\section{III.1. Commercial $\mathbf{P}_{123}$}

Three independent signals with number average molecular weights of $\mathrm{M}=16760,4833$, and $1638 \mathrm{Da}$ (Dalton) and very low polydispersity (PDI index of 1.041, 1.047, and 1.097 respectively) are observed (analysis under gel permeation relative to polystyrene). The observed "molecular weights" only give qualitative information. They are introduced here to demonstrate that 
three distinct polymers are present in a diluted solution of commercial $\mathrm{P}_{123}$ (stored at air temperature) and also because they indicate that the three fractions are homogeneous. The most represented fraction, with a measured molecular weight of 4833 $\mathrm{Da}$, corresponds to monomeric $\mathrm{P}_{123}$ molecules, unimers (the mean commercial molecular weight is equal to 5830 g. $\mathrm{mol}^{-1}$ ), 5 wt. \% corresponds to heavier polymers, blocks of three molecules, at least for a molecular weight of $16760 \mathrm{Da}$, and then possibly heavier fragments corresponding to intertwined polymers or micelles. A very light polymer with a molecular weight of $1638 \mathrm{Da}\left(1700 \mathrm{~g}_{\mathrm{mol}}{ }^{-1}\right)$ rather corresponds to small defects of polymerization. For comparison, a chain of 20 ethylene oxide moieties corresponds to a molecular weight of $1760 \mathrm{~g}$. $\mathrm{mol}^{-1}$.

To confirm if these defects of polymerization observed by chromatography in a polar solvent are also visible when a less polar solvent is used, we have applied ${ }^{1} \mathrm{H}$ and ${ }^{13} \mathrm{C}$ liquid-state NMR to the commercial $\mathrm{P}_{123}$ sample diluted in $\mathrm{C}_{6} \mathrm{D}_{6}(1 \mathrm{wt}$. \%). Although ${ }^{1} \mathrm{H}$ NMR is generally preferred because of its sensitivity, the ${ }^{13} \mathrm{C}$ NMR is a well-known tool to obtain information about the conformation of polymers. Spectra obtained by ${ }^{1} \mathrm{H}$ DOSY NMR (not shown) confirms the predominant presence of $\mathrm{P}_{123}$ unimers (no aggregation, at the used temperature and concentration). Four ${ }^{1} \mathrm{H}$ peaks are observed at 1.20, 3.41, 3.50 and 3.60 ppm. The first ${ }^{13} \mathrm{C}$ signal at $17.80-17.88 \mathrm{ppm}$ is composed of two peaks and attributed to $\mathrm{CH}_{3}-\mathrm{PPO}$ groups while one narrow peak at $71.01 \mathrm{ppm}$, three peaks at 73.54, 73.62 (small and equal intensities) and 73.86 (larger intensity) ppm, with an averaged position at $73.70 \mathrm{ppm}$, and three close peaks at $75.59,75.73$ and $75.84 \mathrm{ppm}$, with an averaged position at $75.72 \mathrm{ppm}$, are observed. While this multiplicity of peaks might look like couplings with several ${ }^{1} \mathrm{H}$ neighbors, obviously it is not the case here since the spectrum has been ${ }^{1} \mathrm{H}$ decoupled. Associated peaks (multiplets) are therefore rather due to the superposition of different signals due to $\mathrm{CH}-\mathrm{PPO}, \mathrm{CH}_{2}-\mathrm{PPO}$ and $\mathrm{CH}_{2}-\mathrm{PEO}$, with chemical shifts induced by different conformational environments, as reported for PEO [30], PPO [31] and PLURONIC triblock polymers [32]. $\left\{{ }^{1} \mathrm{H}\right\}-{ }^{13} \mathrm{C}$ INEPT spectrum (fig 4a) displayed positive peaks at 17.84 and $75.72 \mathrm{ppm}$, attributed to $\mathrm{CH}_{3}-\mathrm{PPO}$ and $\mathrm{CH}-\mathrm{PPO}$, respectively. The peaks centered at 71.01 and $73.67 \mathrm{ppm}$ are negative and correspond either to $\mathrm{CH}_{2}-\mathrm{PEO}$ or to $\mathrm{CH}_{2}-\mathrm{PPO}$ groups. A $2 \mathrm{D}\left\{{ }^{13} \mathrm{C}\right\}-{ }^{1} \mathrm{H}$ HSQC short range ${ }^{1} \mathrm{~J}_{\mathrm{H}-}$ c correlation was undergone to discriminate the two groups. The obtained spectrum, shown in Figure 1a, is similar to one previously published [32]. However, ${ }^{1} \mathrm{H}^{-13} \mathrm{C}$ associations were different in our work, probably due to the different solvent used (polar $\mathrm{D}_{2} \mathrm{O}$ for $\mathrm{Ma}$ et al. in [32], less polar $\mathrm{C}_{6} \mathrm{D}_{6}$ for our experiments). One can notice that at $73.67 \mathrm{ppm}$, the ${ }^{13} \mathrm{C}$ peak correspond to two distinct ${ }^{1} \mathrm{H}$ peaks, located at 3.41 and $3.61 \mathrm{ppm}$. These two peaks agree with an attribution to $\mathrm{CH}_{2}-\mathrm{PPO}$ groups. These groups indeed contain an asymmetric carbon and a possible coupling between the ester $\mathrm{O}$ atoms and a proton of vicinal $\mathrm{CH}_{3}$ groups can block the conformation and induce two magnetically non-equivalent ${ }^{1} \mathrm{H}$ nuclei in the nearby $\mathrm{CH}_{2}$ group. The single peak near $71.01 \mathrm{ppm}$ corresponds to $\mathrm{CH}_{2}$-PEO. Interestingly, small peaks are observed near this latter peak, and are symbolized by diamonds in Figure 1a. They can be attributed to PEO free fragments.

To confirm this attribution and that these fragments do not interact with the remaining intact polymers, a $2 \mathrm{D}{ }^{13} \mathrm{C}-{ }^{1} \mathrm{H}$ HMBC long-range ${ }^{2-3} \mathrm{~J}_{\mathrm{H}-\mathrm{C}}$ experiment is necessary (Figure 1b) [33]. In that figure, the carbon at $73.67 \mathrm{ppm}$ is in contact with the hydrogen at $3.59 \mathrm{ppm}$. Reciprocally, the carbon at $75.72 \mathrm{ppm}$ is in contact with the hydrogen atoms at 3.61 and $3.41 \mathrm{ppm}$. Both correlations are characteristic of PPO groups. On the other hand, the ${ }^{13} \mathrm{C}$ signal at $71.01 \mathrm{ppm}$ is correlated with the ${ }^{1} \mathrm{H}$ at 3.50 ppm. Two additional surrounding signals, marked with clubs are due to residual HMQC ${ }^{1} \mathrm{~J}_{\mathrm{H}, \mathrm{C}}$ peaks [33]. Quantitative information about the weight percentage of PEO units was directly obtained by the integration of the surface areas of ${ }^{13} \mathrm{C}$ resonance at $71.01 \mathrm{ppm}$ (two carbons per EO unit) and $17.84 \mathrm{ppm}$ (single carbon per PO unit), as summarized in Table 2. While $\mathrm{P}_{123}$ formulae gives a calculated $\mathrm{EO} /(\mathrm{EO}+\mathrm{PO})$ ratio of $30 \mathrm{wt}$. \%, a value of $34 \mathrm{wt}$. \% was measured for the sample investigated herein. A similar value of 34 wt. \% was obtained by ${ }^{1} \mathrm{H}$ resonances integration, as described by A. Mathias and N. Mellor in 1966 [34]. The commercial product is thus provided with a small enrichment in EO or PEO units as compared with chemical formula of $\mathrm{P}_{123}$. This observation confirms the presence of a very small amount of uncondensed units even in a non-polar $\mathrm{C}_{6} \mathrm{D}_{6}$ solvent. 

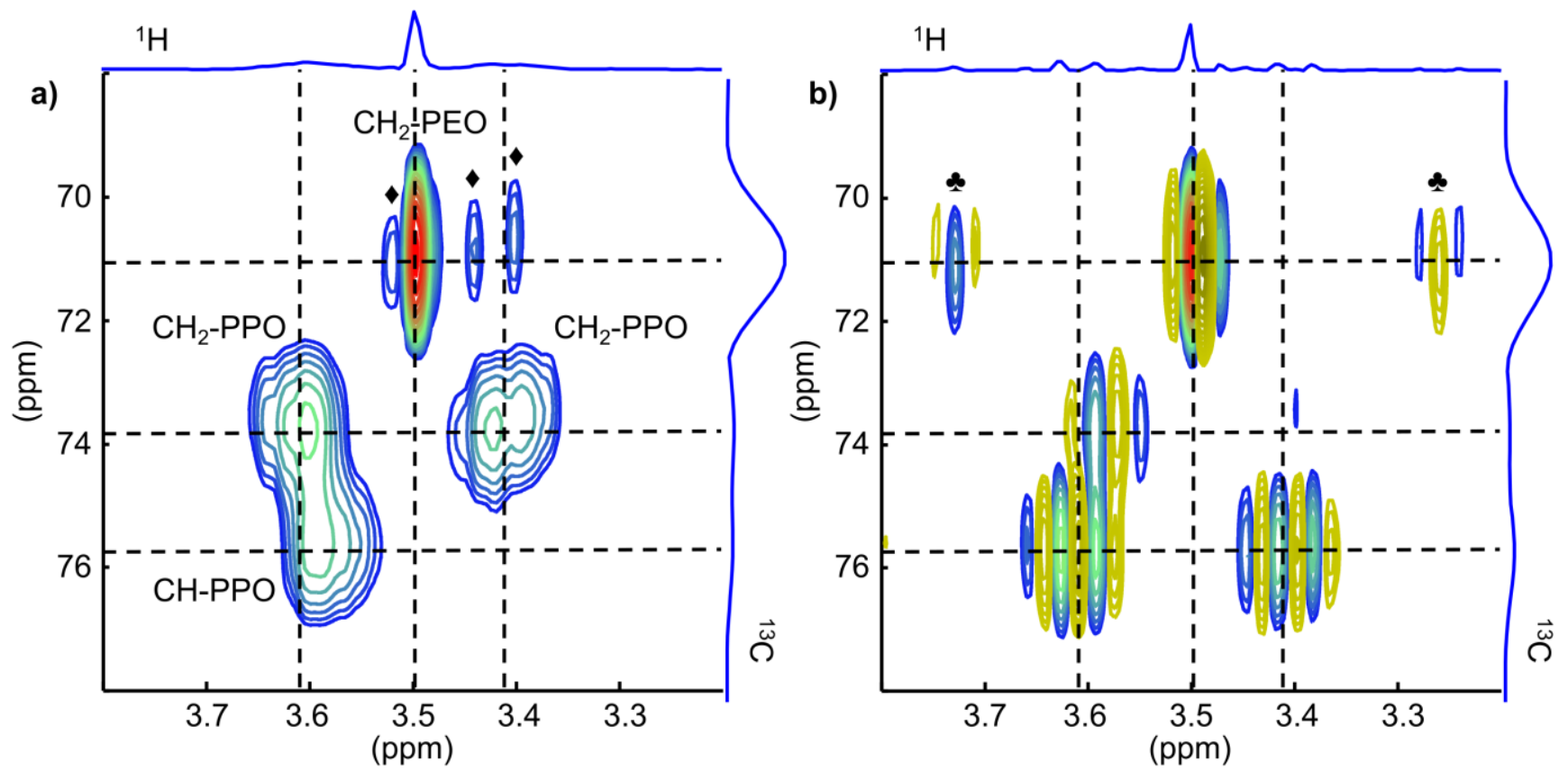

Fig. 1. Attribution of NMR peaks corresponding to diluted $\mathrm{P}_{123}$ in $\mathrm{C}_{6} \mathrm{D}_{6}$ in ${ }^{13} \mathrm{C}$ liquid-state NMR spectra. a) $\left\{{ }^{13} \mathrm{C}\right\}-{ }^{1} \mathrm{H} \mathrm{HSQC}$ short range correlation. $\$$ : EO fragments. b) ${ }^{13} \mathrm{C}-{ }^{1} \mathrm{H}$ HMBC long-range correlation. $\$$ : residual ${ }^{1} \mathrm{~J}_{\mathrm{H}-\mathrm{C}} \mathrm{HMQC}$ correlation. Top and right : positive projections. Parameters: a) $\mathrm{B}_{0}=7.0 \mathrm{~T}, \mathrm{RD}=1 \mathrm{~s}, \mathrm{NS}=1,256$ slices, b) $\mathrm{B}_{0}=7.0 \mathrm{~T}, \mathrm{RD}=1 \mathrm{~s}, \mathrm{NS}=2,256$ slices.

Table 2. Summary of NMR results: ${ }^{13} \mathrm{C}$ signals positions of $\mathrm{CH}_{3}-\mathrm{PPO}, \mathrm{CH}_{2}-\mathrm{PEO}, \mathrm{CH}_{2}-\mathrm{PPO}$ and $\mathrm{CH}-\mathrm{PPO}$ groups and observed $\mathrm{PEO} /(\mathrm{PEO}+\mathrm{PPO})$ molar ratios. By comparison, in theory, the molar PEO/ (PEO + PPO) ratio is equal to 30.2

\begin{tabular}{|c|c|c|c|c|c|}
\hline \multirow[b]{2}{*}{ Sample } & \multicolumn{4}{|c|}{${ }^{13} \mathrm{C}$ signal position (ppm) } & \multirow{2}{*}{$\begin{array}{l}\mathrm{PEO} /(\mathrm{PEO}+\mathrm{PPO}) \\
\text { Molar ratio (wt. \%) }\end{array}$} \\
\hline & $\begin{array}{l}\mathrm{CH}_{3-} \\
\mathrm{PPO}\end{array}$ & $\begin{array}{l}\mathrm{CH}_{2-} \\
\mathrm{PEO}\end{array}$ & $\begin{array}{l}\mathrm{CH}_{2-} \\
\mathrm{PPO}\end{array}$ & $\begin{array}{l}\mathrm{CH}- \\
\mathrm{PPO}\end{array}$ & \\
\hline $\begin{array}{c}\mathrm{P}_{123} \text { in } \mathrm{C}_{6} \mathrm{D}_{6}(1 \mathrm{wt} . \\
\%)\end{array}$ & $\begin{array}{l}17.80 \\
17.88\end{array}$ & 71.01 & $\begin{array}{l}73.54 \\
73.62 \\
73.86\end{array}$ & $\begin{array}{l}75.59 \\
75.73 \\
75.84\end{array}$ & 34 \\
\hline $\begin{array}{l}\text { A_U, stored } 13 \\
\text { months in air* }\end{array}$ & 17.41 & 70.53 & $\begin{array}{l}73.30 \\
73.52\end{array}$ & $\begin{array}{l}75.59 \\
75.70 \\
75.81\end{array}$ & 21 \\
\hline A_HT90_dried70_ & 17.34 & 70.32 & $\begin{array}{l}73.15 \\
73.33\end{array}$ & 75.30 & 20 \\
\hline $\begin{array}{c}\text { A_HT130_dried70 } \\
\text { U }\end{array}$ & 17.37 & 70.36 & $\begin{array}{l}73.16 \\
73.34 \\
\end{array}$ & 75.30 & 16 \\
\hline B_U & 17.24 & 69.76 & $\begin{array}{l}72.91 \\
73.09\end{array}$ & 75.18 & 30 \\
\hline C_U & 17.31 & 70.09 & $\begin{array}{l}73.09 \\
73.27\end{array}$ & 75.22 & 30 \\
\hline E_HT90_U & 17.27 & 70.40 & $\begin{array}{l}73.03 \\
73.21\end{array}$ & 75.18 & 26 \\
\hline F_U (EISA) & 17.33 & 70.36 & $\begin{array}{l}73.05 \\
73.24\end{array}$ & 75.25 & 27 \\
\hline
\end{tabular}

\section{III.2. NIR study}

NIR is a rapid analytical tool and gives direct information about the composition of organic polymers and PEO/PPO ratio in Pluronic block copolymers. To simplify attributions, spectra were empirically divided into six spectral ranges that are identical 
to those defined to describe the NIR spectra of oils and fatty acids [20] (Figure 2). Thus, the six ranges are: i) range X: below $1100 \mathrm{~nm}$; ii) range A: 1100 - $1300 \mathrm{~nm}$; iii) range B: 1300 - $1600 \mathrm{~nm}$; iv) range C: 1600 - $1850 \mathrm{~nm}$; v) range D: 1850 - 2050 $\mathrm{nm}$; vi) range $\mathrm{E}: 2050$ - $2230 \mathrm{~nm}$; vii) range $\mathrm{F}: 2230$ - $2500 \mathrm{~nm}$.

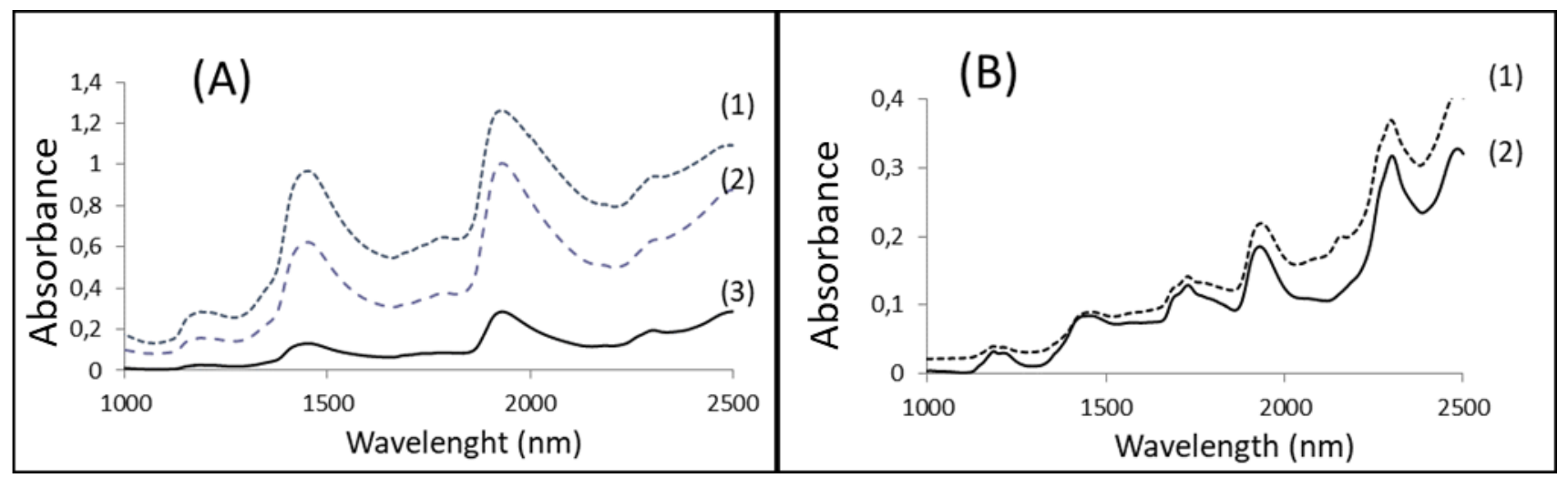

Fig.2. NIR spectra measured with a diffuse reflectance cell (internal, $7 \mathrm{~cm}$ diameter) and using Teflon PTFE as a reference. (A) - Precipitated hybrids: (1) B_HT130_U, (2) D_HT130_U, (3) B_U. (B) -Two other fresh hybrids: (1) E_HT100_U and (2) F_U

Water molecules are identified in D range while the silanols terminal groups are in B range; range A has been particularly studied for the detection of organic acids, such as citric, tartaric or malic acids in water solutions [21]. Recent detailed studies on polymers, $\mathrm{R}$ alkyl chains with ending carboxylic groups and their interactions with water can be particularly interesting since $\mathrm{R}-\mathrm{COOH}$ groups are transformed into $\mathrm{R}_{-} \mathrm{COO}^{-}$groups as a function of applied $\mathrm{pH}$ : a simple $\mathrm{pH}$ adjustment then change the hydrophilic character of the polymers and its possible affinity for proteins interactions [35]. In range $\mathrm{C}$, three peaks are observed in hydrated samples: 1702,1745 and $1810 \mathrm{~nm}$ and can be attributed to $\mathrm{CH}_{3}, \mathrm{CH}_{2}$ and $\mathrm{CH}_{2}-\mathrm{O}$ groups, respectively, involved in H-bounds in which water molecules are participating. In dehydrated samples, two major vibrations are observed at 1929 and $1802 \mathrm{~nm}$ with a small additional shoulder at $1730 \mathrm{~nm}$ for the spectra of F_U and B_dried70_U. Ranges D and E give only limited information, because of a main contribution attributed to water. Range F contains small contributions in hydrated samples, at ca. 2275 and $2308 \mathrm{~nm}$.

In dehydrated samples, stronger vibrations within the range 2240 to $2360 \mathrm{~nm}$ and within the range 2290 to $2470 \mathrm{~nm}$ can be associated with stretching and bending combinations of $\mathrm{CH}$ bounds in $\mathrm{CH}_{3}$ and in $\mathrm{CH}_{2}$ groups. An additional peak at $2167 \mathrm{~nm}$ is observed in the spectrum of the A_U ( $\mathrm{pH}=0$, unwashed, not shown) after evolution 13 months in air and at room temperature. This NIR peak can be associated with a stretching experienced by $\mathrm{C}=\mathrm{O}$ bonds, in organics like formaldehyde and in carboxylic ending groups. Recent detailed studies about polymers containing R-COOH ending carboxylic groups and their interactions with water are extremely interesting since these groups can be transformed in R-COO- groups under adapted conditions of acidity, a simple adjustment can then change the hydrophilic character of the polymer and its possible affinity for interactions with proteins or other biological molecules [35].

\section{III.3. Organics in fresh samples}

In the present paragraph, we will describe more than 10 samples and give details about their ${ }^{1} \mathrm{H}$ and ${ }^{13} \mathrm{C}$ NMR spectra, as recorded in several conditions. To ensure the readability of this paragraph, Table 2 displays the positions of ${ }^{13} \mathrm{C}$ peaks and also the molar ratios $\mathrm{EO} /(\mathrm{EO}+\mathrm{PO})$ in weight, wt. \% that we have used to describe the acidic hydrolysis at which copolymers have been submitted in our solids.

Six distinct paragraphs are introduced, dealing with the influence of (i) the applied magnetic field strength, (ii) the synthesis conditions, concerning fresh samples without hydrothermal treatment, HT, (iii) the applied hydrothermal treatment, (iv) a 
dehydration treatment, (v) MAS sample spinning on the NMR signals observed on precipitated samples, compared to stable signals obtained with hybrids prepared by EISA, (vi) aging time.

\section{III.3.1. Influence of magnetic field strength}

TEM images and SAXS measurements described in Supplementary Information show that in the hybrids investigated in this work, the ordered and parallel cylindrical mesopores are present in almost all samples. Lamellar silica is observed after strong washing treatments with water. In order to analyze the organic surfactant molecules trapped inside the walls of the ordered 2D hexagonal SBA-15 silica grains, we have first compared the resolution obtained in ${ }^{13} \mathrm{C}$ solid-state NMR with two magnetic field strengths of 7.0 and $16.4 \mathrm{~T}$ (Figure 3). One can notice that the spinning rate was $v_{\mathrm{r}}=5 \mathrm{kHz}$ at $7.0 \mathrm{~T}$ and $v_{\mathrm{r}}=22 \mathrm{kHz}$ at 16.4 T. However, this should not influence the peak widths as both spectra were ${ }^{1} \mathrm{H}$ decoupled. Additionally, $v_{\mathrm{r}}=5 \mathrm{kHz}$ at 7.0 $\mathrm{T}$ is enough to remove the spinning side bands of $\mathrm{sp}^{3}$ hybridized carbon atoms due to their Chemical Shift Anisotropy (CSA). The increase of magnetic field narrowed the peaks, especially that at ca. $73 \mathrm{ppm}$. Consequently, it is possible to discriminate two signals at 73.2 and $73.0 \mathrm{ppm}$ due to $\mathrm{CH}_{2}$-PPO groups when a magnetic field of $16.4 \mathrm{~T}$ is applied. The upper peak is narrower than the lower one. By similarity with liquid-state NMR and reported data, the peak at 73.0 ppm is associated with $\mathrm{g}^{+}$and $\mathrm{g}^{-}$conformations while the peak at $73.2 \mathrm{ppm}$ corresponds to trans conformation around C-C bonds in O-C-C-O sequence. Hence, it is evident that a good quality sample and also a high magnetic field are necessary to observe this improved spectral resolution.

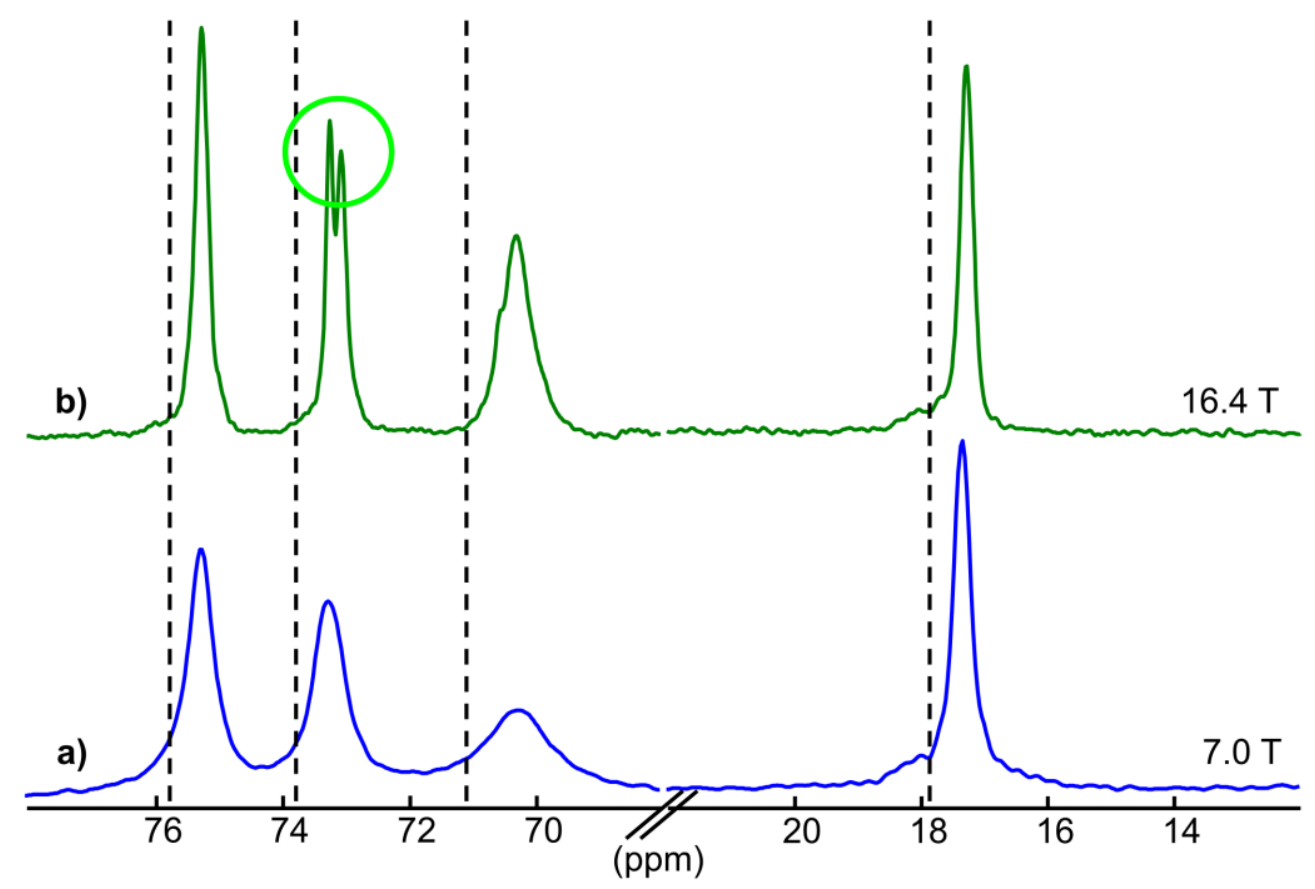

Fig. 3. Influence of magnetic field strength. ${ }^{13} \mathrm{C}$ HPDEC solid-state NMR spectra of a) A_U at $\mathrm{B}_{0}=7.0 \mathrm{~T}$, b) Same sample at $\mathrm{B}_{0}=16.4 \mathrm{~T}$. Dashed line: ${ }^{13} \mathrm{C}$ signals positions for a diluted solution of $\mathrm{P}_{123 i n} \mathrm{C}_{6} \mathrm{D}_{6}$; Parameters: $\left.\mathrm{LB}=10 \mathrm{~Hz}, \mathrm{a}\right) \mathrm{RD}=10 \mathrm{~s}, \mathrm{NS}=9216, v_{\mathrm{r}}=5 \mathrm{kHz}, \mathrm{b}$ ) $\mathrm{RD}=3 \mathrm{~s}, \mathrm{NS}=4016$ and $v_{\mathrm{r}}=22 \mathrm{kHz}$.

\section{III.3.2. Influence of synthesis conditions}

A liquid spectrum is collected on $\mathrm{P}_{123}(1 \mathrm{wt} \%)$ diluted in $\mathrm{C}_{6} \mathrm{D}_{6}$. This spectrum is compared with solid spectra recorded on precipitated (b) A_U, (c) B_U and (e) E_HT100_U hybrids and (f) on F_U (Figure 4). Negative and positive peaks, corresponding to $\mathrm{CH}_{2}$ and $\mathrm{CH}, \mathrm{CH}_{3}$ groups, respectively, are useful for the identification of $\mathrm{CH}-\mathrm{PPO}$ and $\mathrm{CH}_{3}-\mathrm{PPO}$ (both positive) 
and $\mathrm{CH}_{2}$-PEO and $\mathrm{CH}_{2}$-PPO both negative, except in the spectrum displayed in Figure 4d which has been recorded with a different re-focalization time. Spectra of $\mathrm{P}_{123}$ molecules in $\mathrm{C}_{6} \mathrm{D}_{6}$ solution (Figure $4 \mathrm{a}$ ) can be compared to that of $\mathrm{P}_{123}$ trapped into 2D hexagonal SBA-15 silica solid grains, with no applied HT and obtained in HCl 2 mol.L-1 (Figure 4b). Peak positions are summarized in Table 2. Trapped surfactant molecules in silica had lower position values and larger width than in $\mathrm{C}_{6} \mathrm{D}_{6}$ solution [26]. Indeed, $\mathrm{C}_{6} \mathrm{D}_{6}$ is a poorly polar solvent whereas polar $\mathrm{H}_{2} \mathrm{O}$ molecules are surrounding and protecting the organic units inside the grains of hybrids. In particular, the $\mathrm{CH}-\mathrm{PPO}$ peak was shifted upfield by 0.5 ppm, which suggested that in $\mathrm{C}_{6} \mathrm{D}_{6}$ and at the used concentration and temperature, $\mathrm{P}_{123}$ molecules are forming aggregates or micelles. A main difference is observed for the peaks attributed to $\mathrm{CH}_{2}-\mathrm{PPO}$ groups. The intensity of the trans conformation around the $\mathrm{C}-\mathrm{C}$ bond in the solid is less important than in solution. The splitting between the two gauche conformations around this bond is also less important. Two narrow peaks at 73.5 and $75.0 \mathrm{ppm}$ seen in solution and in the spectrum in Figure $4 \mathrm{~b}$, are due to extreme EO moieties at the end of the PEO chains [32]. Figures 4d-e correspond to hybrids prepared in different conditions, namely using constant stirring upon aging and spray drying, respectively. They both exhibit a similar downfield shift of 0.6 and 0.2 ppm for $\mathrm{CH}_{2}-$ PEO and $\mathrm{CH}_{2}-\mathrm{PPO}$ groups, respectively, as compared to sample B_U. The signal due to the CH-PPO is also downfield, like in washed B_U, denoting an association between the dehydrated PEO chains and the hydrophobic core of the micelles as well as the formation of a non-polar microenvironment around PPO groups.

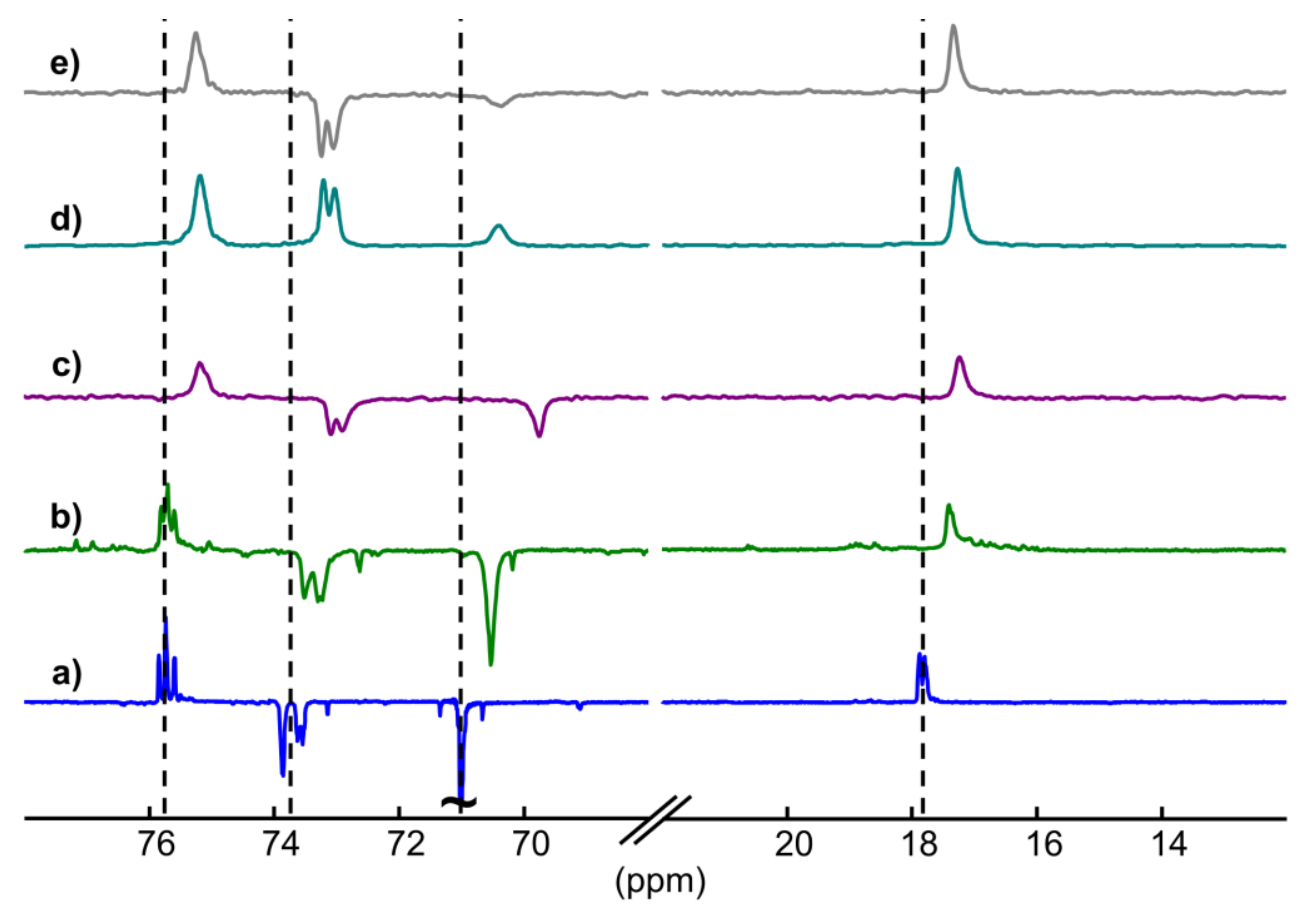

Fig. 4: Influence of sample synthesis. ${ }^{13} \mathrm{C}$ INEPT NMR spectra of a) solution 1 wt. $\%$ of $\mathrm{P}_{123}$ diluted in $\left.\left.\left.\mathrm{C}_{6} \mathrm{D}_{6}, \mathrm{~b}\right) \mathrm{A} \_\mathrm{U}, \mathrm{c}\right) \mathrm{B} \_\mathrm{U}, \mathrm{d}\right)$ E_HT90_dried70_U, e) F_U. Parameters: a, b) NMR at B0 = 7.0 T, c, d, e) solid-state NMR at B0 = 16.4 T, vr = 20-22 kHz, a, b, c, e) CH and $\mathrm{CH}_{3}$ upside, $\mathrm{CH}_{2}$ downside, d) $\mathrm{CH}, \mathrm{CH}_{2}, \mathrm{CH}_{3}$ upside.

\section{III.3.3. Influence of applied hydrothermal treatment}

We have prepared a single hybrid that was splitted into three fractions for which hydrothermal treatments (HT) at different temperatures and times have been applied. Afterwards, quantitative ${ }^{13} \mathrm{C}$ solid-state NMR measurements were undergone (Figure 5). Interestingly, a chemical shift from 0.14 to 0.18 ppm was observed for $\mathrm{CH}_{3}-\mathrm{PPO}, \mathrm{CH}_{2}-\mathrm{PEO}$ and $\mathrm{CH}_{2}-\mathrm{PPO}$ after $\mathrm{HT}$. The observed shift was even stronger at $130^{\circ} \mathrm{C}$ than at $90^{\circ} \mathrm{C}(24 \mathrm{~h})$. No shift was detected for the signal due to $\mathrm{CH}-\mathrm{PPO}$, which is consistent with the idea that these peculiar groups are protected inside hydrophobic pockets and therefore not altered or 
modified by the HT. Additionally, peaks corresponding to $\mathrm{CH}$ and $\mathrm{CH}_{2}$ are broader, as evidenced by the decreased resolution between the peaks due to several conformations of $\mathrm{CH}_{2}-\mathrm{PPO}$ groups. This shift and broadening are similar to the ones observed in Figures 4c, 4d and 4e and indicate a decreased mobility. Results displayed in Figure 5 are coherent with a progressive growth of the micellar core, i.e., a partial retraction of the dehydrated PEO moieties from inside silica walls to inside central organic micelles. The addition of PEO units to the hydrophobic part of the micelles is consistent with a decreased intensity (less mobile). It corresponds to an increase in size of mesopores as detected by $\mathrm{N}_{2}$ sorption (after organic removal by calcination, see next paragraph) for A_C and A_HT130_C samples, for instance. In conclusion, when a HT treatment at $130^{\circ} \mathrm{C}$ is applied for $24 \mathrm{~h}$, some of the PEO units, initially hydrated, are dehydrated and extracted from silica walls. It was not the case if a simple dehydration treatment at $70^{\circ} \mathrm{C}$ for $26 \mathrm{~h}$ was applied, but in that case the architecture is decomposed and PEO chains remain blocked inside amorphous silica walls.

All the peaks lose some intensity, gaining in line width but there is a particular decrease of the intensity and an increase of the line-width of the peak due to $\mathrm{CH}_{2}$-PEO, significantly losing in mobility. As made for solutions, we have measured the PEO/ (PEO + PPO) ratio using ${ }^{13} \mathrm{C} \mathrm{CH}_{2}$-PEO and $\mathrm{CH}_{3}$-PPO peaks. We obtained 29.2, 20.8, and 16.8 wt. \% for three washed samples without HT, with HT at 90 and $130^{\circ} \mathrm{C}$, respectively. These values can be compared with the calculated one, $30.1 \%$. The lower values are denoting that $\mathrm{P}_{123}$ polymer has been at least partially decomposed. The liberated $\mathrm{PEO}$ and organic fragments present in solution have been removed during the sample washing. The aqueous washing solutions are mainly enriched in 1,2-ethanediol. The washing solutions isolated with ethanol are much more complex and their analysis is out of the present work.

An acidic hydrolysis of both PEO and PPO chains induces a decrease of micelles core polarity and retracts residual PEO chains. Moreover, a clear decrease of porosity is observed and depends on the temperature of the applied HT (Table 3). A progressive decrease of porosity occurring when sample was washed with water is indicated by $\mathrm{N}_{2}$ sorption data summarized in Supplementary Information. The incidence of washing conditions is less important for the evaporated $F_{-}$U sample, whose porosity is only poorly affected by washing with more than $6 \mathrm{~L}$ of water.

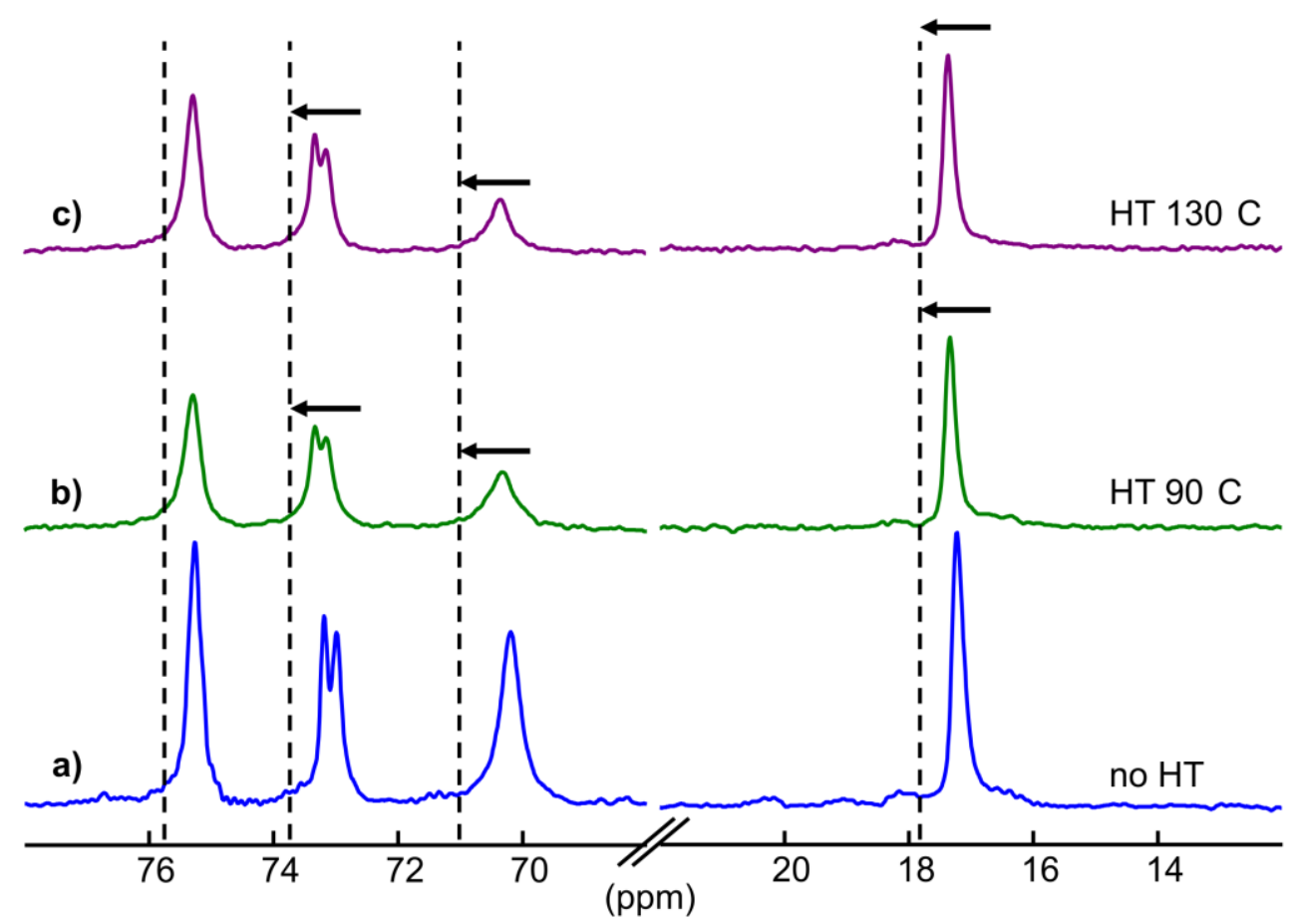

Fig. 5. Influence of hydrothermal treatment. ${ }^{13} \mathrm{C}$ HPDEC solid-state NMR spectra a) no HT (A_U), b) HT 90 ${ }^{\circ} \mathrm{C}\left(\mathrm{A} \_\right.$HT90_U), c) HT $130^{\circ} \mathrm{C}$ (A_HT130_U). Dashed line: diluted solution of $\mathrm{P}_{123}$ in $\mathrm{C}_{6} \mathrm{D}_{6}$. Arrows to indicate very small peaks shifts. Parameters: $\mathrm{B} 0=16.4 \mathrm{~T}$,

$$
\mathrm{RD}=3 \mathrm{~s}, \mathrm{NS}=1024, \mathrm{LB}=10 \mathrm{~Hz}, \mathrm{v}_{\mathrm{r}}=22 \mathrm{kHz}
$$


Table 3. Textural properties evaluated by $\mathbf{N}_{2}$ sorption and SAXS measurements. Chlorine contamination indicated in two model samples (in wt. \% or ppm)

\begin{tabular}{|c|c|c|c|c|c|c|c|}
\hline Sample & Calcination & $\begin{array}{r}\mathrm{S}_{\mathrm{BET}} \mathrm{a}^{\mathrm{a}} \\
\left(\mathrm{m}^{2} \cdot \mathrm{g}^{-1}\right) \\
\end{array}$ & $\begin{array}{c}\mathrm{V}_{\mathrm{p}}^{\mathrm{b}} \\
\left(\mathrm{cm}^{3} \cdot \mathrm{g}^{-1}\right) \\
\end{array}$ & $\begin{array}{c}\mathrm{V}_{\mu}^{\mathrm{c}} \\
\left(\mathrm{cm}^{3} \cdot \mathrm{g}^{-1}\right) \\
\end{array}$ & $\begin{array}{c}\mathrm{D}^{\mathrm{d}} \\
(\mathrm{nm})\end{array}$ & $\begin{array}{c}\mathrm{a}^{\mathrm{e}} \\
(\mathrm{nm})\end{array}$ & $\begin{array}{c}\mathrm{Cl} \\
(\mathrm{wt} \%) \\
\end{array}$ \\
\hline $\begin{array}{l}\text { A_U (HCl } 1.9 \text { mol.L- } \\
\left.{ }^{1}\right) \_ \text {stored } 13 \text { months in } \\
\text { air then calcined }\end{array}$ & $\begin{array}{l}\text { RT to } 500^{\circ} \mathrm{C} \\
\text { (in } 4 \mathrm{~h} \text { ), then } 6 \\
\mathrm{~h} \text { at } 500^{\circ} \mathrm{C}\end{array}$ & 476 & 0.45 & 0.03 & 3.7 & 12.5 & 0.33 \\
\hline $\begin{array}{l}\text { A_U_ stored } 1 \text { month in } \\
\text { air then calcined }\end{array}$ & $\begin{array}{l}\text { RT to } 500^{\circ} \mathrm{C} \\
\text { (in } 4 \mathrm{~h} \text { ), then } 6 \\
\mathrm{~h} \text { at } 500^{\circ} \mathrm{C}\end{array}$ & 599 & 0.71 & 0.03 & $3.8-5.0$ & 9.8 & \\
\hline $\begin{array}{c}\text { B_U } \\
\text { B_HT130_U }\end{array}$ & Uncalcined & & & & & $\begin{array}{l}12.5 \\
12.0\end{array}$ & \\
\hline B_dried $70^{\circ} \mathrm{C} / 26 \mathrm{~h}$ & $\begin{array}{l}\text { RT to } 500^{\circ} \mathrm{C} \\
\text { (in } 4 \text { h), then } 6 \\
\text { h at } 500^{\circ} \mathrm{C}\end{array}$ & $30<$ & & $0.00(3)$ & $\begin{array}{c}3.0 \\
\text { (barely } \\
\text { visible) }\end{array}$ & & \\
\hline B_C (no HT) & $\begin{array}{l}\text { RT to } 500^{\circ} \mathrm{C} \\
\text { (in } 4 \mathrm{~h} \text { ), then } 6 \\
\text { h at } 500^{\circ} \mathrm{C} \\
\end{array}$ & 738 & 0.64 & 0.16 & 3.7 & 9.8 & \\
\hline B_HT130_C & $\begin{array}{c}\text { Washed with } \\
2 \mathrm{~L} \text { of water } \\
\text { RT to } 500{ }^{\circ} \mathrm{C} \\
\text { (in } 4 \mathrm{~h} \text { ), then } 6 \\
\text { h at } 500^{\circ} \mathrm{C}\end{array}$ & 1332 & 2.88 & $0.04(2)$ & 7.6 & & $347 \mathrm{ppm}$ \\
\hline C_C & $\begin{array}{l}\text { RT to } 500{ }^{\circ} \mathrm{C} \\
\text { (in } 4 \text { h), then } 6 \\
\text { h at } 500^{\circ} \mathrm{C}\end{array}$ & 589 & 0.46 & 0.12 & 3.5 & 9.7 & \\
\hline C_HT130_C & $\begin{array}{l}\text { RT to } 500{ }^{\circ} \mathrm{C} \\
\text { (in } 4 \text { h), then } 6 \\
h \text { at } 500^{\circ} \mathrm{C}\end{array}$ & 904 & 1.92 & 0.03 & 7.9 & & \\
\hline D_HT130_C & $\begin{array}{l}\text { RT to } 500{ }^{\circ} \mathrm{C} \\
\text { (in } 4 \text { h), then } 6 \\
\text { h at } 500^{\circ} \mathrm{C}\end{array}$ & 500 & 1.17 & 0.03 & 8.4 & & \\
\hline E_HT90_C & $\begin{array}{l}\text { Drying at } \\
70^{\circ} \mathrm{C}, 12 \mathrm{~h} \text { be- } \\
\text { fore calcination } \\
500^{\circ} \mathrm{C} \text {, rate } \\
1.33^{\circ} \mathrm{C} / \mathrm{min}, 4 \mathrm{~h}\end{array}$ & 1001 & 1.54 & 0.06 & 7.0 & & \\
\hline E_HT100 ${ }^{\circ} \mathrm{C}_{-} \mathrm{C}^{\prime}$ & $\begin{array}{c}\text { Dried at } 70^{\circ} \mathrm{C}, \\
12 \mathrm{~h} \text { before } \\
\text { calcination } \\
550^{\circ} \mathrm{C} \text {, rate } 1.5 \\
{ }^{\circ} \mathrm{C} / \mathrm{min}, 6 \mathrm{~h}\end{array}$ & 807 & 0.80 & 0.35 & 4.8 & & \\
\hline $\mathrm{F} \quad \mathrm{U}$ & & 169 & 0.37 & 0.01 & 7.6 & & \\
\hline $\begin{array}{r}{ }^{\mathrm{a} S p e c i f i c ~ s u r f a c e} \mathrm{a} \\
{ }^{\mathrm{c}} \text { Microporous } \mathrm{vc} \\
\mathrm{d} \text { Mesopore dia } \\
\mathrm{e} \text { a, unit-cell parameter, ca } \\
\text { using the position of the } \\
\text { lectec }\end{array}$ & $\begin{array}{l}\text { a, determined wi } \\
\text { bTotal porous v } \\
\text { ume, as determin } \\
\text { eter, Barret Joyn } \\
\text { culated for mesor } \\
\text { nost intense diffr } \\
\text { SAXS measurem }\end{array}$ & $\begin{array}{l}\text { in the rans } \\
\text { ume, singl } \\
\text { by } t \text {-plot } \\
\text { and Halen } \\
\text { res ordere } \\
\text { tion peak, } \\
\text { ts are pres }\end{array}$ & $\begin{array}{l}.05-0.30, \text { as } \\
\text { oint determ } \\
\text { ckness of } \mathrm{N} \\
\text { applied to } \mathrm{t} \\
\text { d forming } \\
\text { exed } 100 \text { a } \\
\text { ed in Suppl }\end{array}$ & $\begin{array}{l}\text { ammended } \\
\text { at } \mathrm{P} / \mathrm{P}^{0}=0 \\
\text { culated by } \\
\text { sorption } \mathrm{b} \\
\text { agonal un } \\
\text { e geometri } \\
\text { tary Infor }\end{array}$ & $\begin{array}{l}\text { r mesopo } \\
\text { arkins Jur } \\
\text { ch of the } \\
\text { ell in the } \\
\text { relation: } \\
\text { tion.F U }\end{array}$ & $\begin{array}{l}\text { us sam } \\
\text { formul } \\
\text { otherm } \\
\text { ace gr } \\
=2 * \mathrm{~d}_{1}\end{array}$ & $\begin{array}{l}\text { es } \\
\text { p p6mm } \\
\sqrt{3} \text {. Se- }\end{array}$ \\
\hline
\end{tabular}

\section{III.3.4. Influence of dehydration}

Depending on storage conditions, samples hydration level can strongly vary and it was important to check its influence on $\mathrm{P}_{123}$ mobility inside uncalcined SBA-15 grains stored in air. To answer this question, we have compared the same sample in wet 
and dry conditions. While for the wet state, the sample was stored in a controlled humidity atmosphere, to obtain the dry state, the sample was placed at $70^{\circ} \mathrm{C}$ under a $4 \mathrm{mBar}$ vacuum for $17 \mathrm{~h}$.

${ }^{1} \mathrm{H}$ solid-state NMR spectra are presented in Figure 6. In wet state, Figure 6a, an intense peak was present at 4.49 ppm and can be attributed to $\mathrm{H}_{2} \mathrm{O}$. Additionally, narrow peaks were observed at 1.19, 3.45, 3.60, and 3.79 ppm, denoting the high mobility of the $\mathrm{P}_{123}$ polymer. When zooming into 5 to $10 \mathrm{ppm}$ region (insert), only a new small peak at 7.0 ppm was visible but it could be a shimming artefact of the water peak. No other peak that could be associated with $\mathrm{OH}$ groups strongly $\mathrm{H}-$ linked that exist on the silica surface with distributed bond lengths and angles, like the ones indicated and quantified by the IR measurements that are given in Supplementary Information 4 is detected. Severe line-broadening effect due to ${ }^{1} \mathrm{H}-{ }^{1} \mathrm{H}$ dipolar interactions giving broad NMR peaks have been reported for ${ }^{1} \mathrm{H}$ NMR peaks for the surface defects of Cabo-Sil amorphous silica [36] for instance. Its absence denoted that all $\mathrm{Si}-\mathrm{OH}$ groups were accessible to water molecules and were in fast exchange with them. On the contrary, in dry state, Figure $6 \mathrm{~b}$, no water peak was evidenced and ${ }^{1} \mathrm{H}$ peaks for $\mathrm{P}_{123}$ were broader, especially the one observed at $3.79 \mathrm{ppm}$ while a broad $\mathrm{OH}$ peak was observed at $5.7 \mathrm{ppm}$ (insert). Observed spectral differences indicate that the dehydration was strong enough to remove free water, but not to remove surface silanol OH groups, which were still strongly $\mathrm{H}$-linked with each other (or with remaining water traces). This had a major impact on $\mathrm{P}_{123}$ molecules which became less mobile, as shown by the ${ }^{1} \mathrm{H}$ signal increased line-width, yielding to the disappearance of the signal associated with the $\mathrm{CH}$ PPO group.

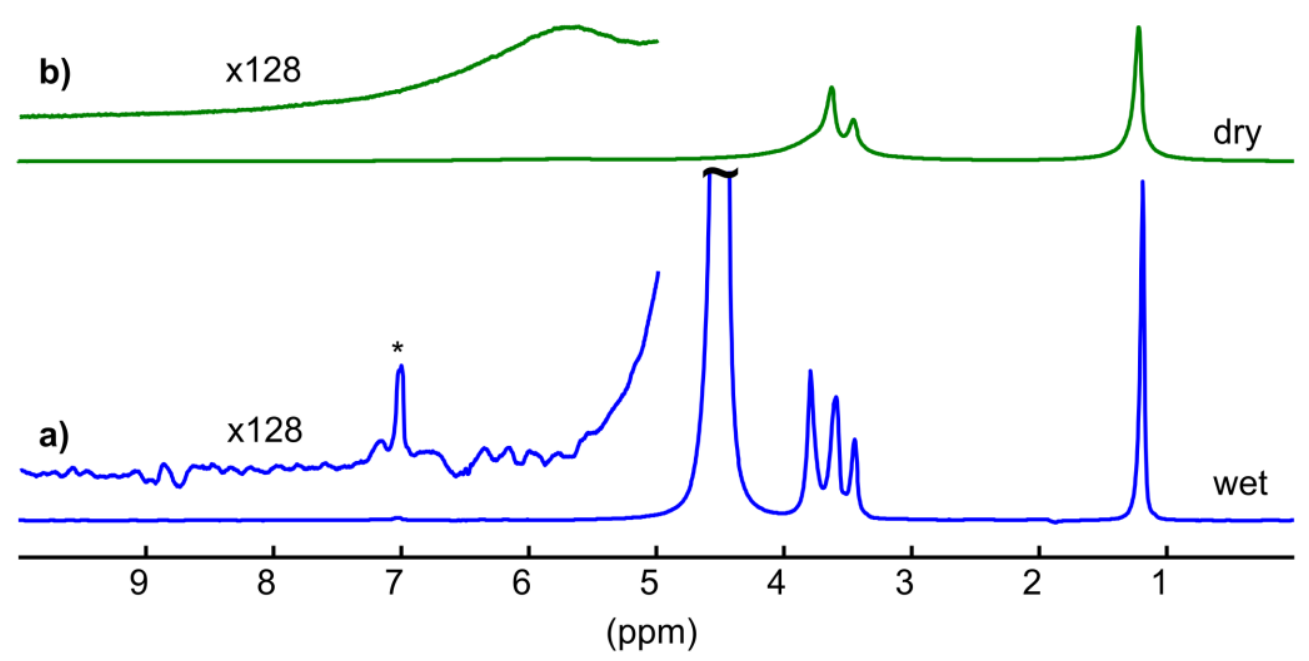

Fig. 6. Influence of dehydration. ${ }^{1} \mathrm{H}$ solid-state NMR spectra of B_U a) stored under controlled humidity (wet), b) after $17 \mathrm{~h}$ at $70^{\circ} \mathrm{C}$ under a 4 mBar vacuum (dry), * shimming artefact of peak at 4.49 ppm. Parameters: $\mathrm{B}_{0}=16.4 \mathrm{~T}, \mathrm{RD}=10 \mathrm{~s}, \mathrm{NS}=8, \mathrm{LB}=2 \mathrm{~Hz}, \mathrm{v}_{\mathrm{r}}=20 \mathrm{kHz}$.

${ }^{13} \mathrm{C}$ solid-state NMR (Figure 7) confirmed the differences between the mobility of $\mathrm{P}_{123}$ in wet and dry samples. Three different experiments were undergone for each state, on the same sample, namely HPDEC (a and d), INEPT (b and e), and CP (c and f). These experiments are complementary: while HPDEC technique is quantitative and display peaks corresponding to the amount of carbon, INEPT and CP are qualitative techniques showing peaks highlighting mobile and rigid molecular parts of the polymer, respectively. In wet state Figure 7a, 7b, and 7c, narrow lines were observed, the INEPT signal was strong while the CP signal was inexistent. This clearly evidenced a high mobility of both PEO and PPO parts of the polymer. In dry state Figure 7d, 7e, and 7f, broad lines were presented, especially for $\mathrm{CH}_{2}-\mathrm{PEO}$ at $70.10 \mathrm{ppm}$. This peak was absent in INEPT and enhanced in $\mathrm{CP}$, which evidenced a rigid part. By comparing the broadening between ${ }^{1} \mathrm{H}$ and ${ }^{13} \mathrm{C}$ spectra, the ${ }^{1} \mathrm{H}$ peak at 3.79 ppm can be attributed to $\mathrm{CH}_{2}-\mathrm{PEO}$. $\mathrm{CH}_{2}-\mathrm{PPO}$ at $73.13 \mathrm{ppm}$ and $\mathrm{CH}-\mathrm{PPO}$ at $75.22 \mathrm{ppm}$ were weakly visible on both INEPT and CP spectra, which correspond to an intermediate mobility. Additionally, it was noticed that the drying induced peak shifts 
to higher values, of $0.07,0.33,0.18$, and $0.04 \mathrm{ppm}$ for $\mathrm{CH}_{3}-\mathrm{PPO}, \mathrm{CH}_{2}-\mathrm{PEO}, \mathrm{CH}_{2}-\mathrm{PPO}$, and $\mathrm{CH}-\mathrm{PPO}$. Both PEO and PPO chains were initially hydrated (even in a sample let for drying in air for more than $24 \mathrm{~h}$ ) and the observed chemical shift changes reflected a modification of their magnetic environment, their associated H-bonds and hence, of their conformation. H-bonds could be either intramolecular (involving ether oxygen and protons of $\mathrm{CH}_{3}$ groups in $\mathrm{PPO}$ ), with surrounding water, or with $\mathrm{Si}-\mathrm{OH}$ defects from silica. The conformational change could be induced during the PEO retraction. It is not possible to discriminate which effect is predominant here.

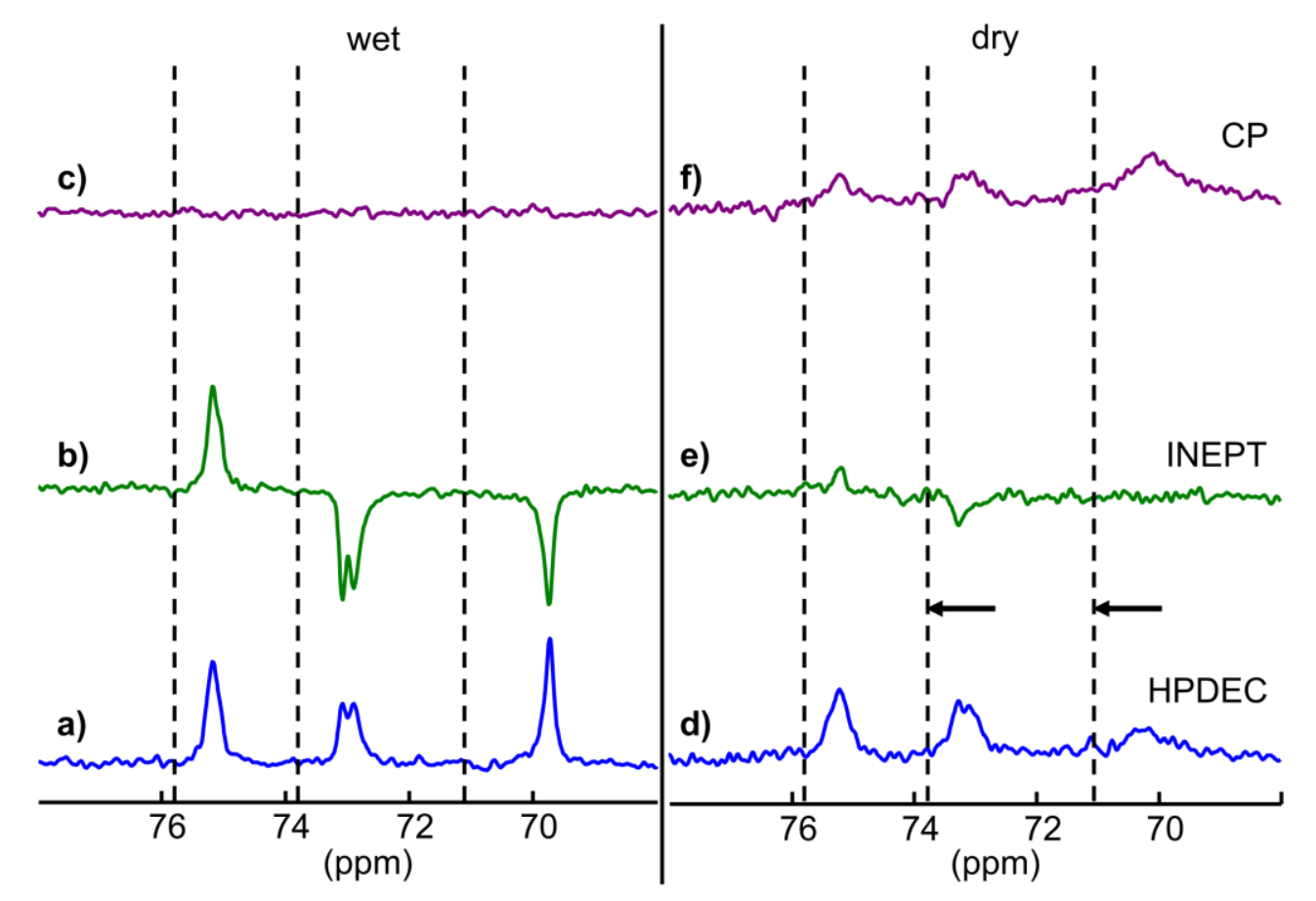

Fig. 7. Influence of dehydration. ${ }^{13} \mathrm{C}$ solid-state NMR spectra of washed B_U sample a) b) c) stored under controlled humidity (wet), d) e) f) after $17 \mathrm{~h}$ at $70^{\circ} \mathrm{C}$ under a $4 \mathrm{mBar}$ vacuum (dry); a) d) HPDEC, b) e) INEPT, c) f) CP. Dashed line: diluted solution of $\mathrm{P}_{123}$ in $\mathrm{C}_{6} \mathrm{D}_{6}$.

Arrows: peak shifts. Parameters: $\left.\left.\left.\mathrm{B}_{0}=16.4 \mathrm{~T}, \mathrm{RD}=3 \mathrm{~s}, \mathrm{NS}=128, \mathrm{LB}=10 \mathrm{~Hz}, \mathrm{v}_{\mathrm{r}}=20 \mathrm{kHz}, \mathrm{c}\right), \mathrm{f}\right) \mathrm{t}_{\mathrm{cp}}=1 \mathrm{~ms}, \mathrm{f}\right) \mathrm{NS}=1536$.

\section{III.3.5. Unexpected influence of MAS sample spinning}

${ }^{1} \mathrm{H}$ MAS NMR spectra of hybrids obtained by precipitation are very sensitive to drying and evolved spontaneously as a function of spinning time inside the NMR rotor. This is illustrated by the two spectra shown in Figure 8, where (a) is the spectrum collected just after introduction inside the NMR apparatus and (b) is the spectrum collected after $56 \mathrm{~h}$ of spinning. The intensity of the large water peak at circa 5.0 ppm was significantly decreased as highlighted by the black arrow. This evidenced that an unexpected dehydration occurred inside the NMR rotor. This can be explained by the fact that the rotor cap was not perfectly sealed and small water molecules could diffuse outside of the rotor and be trapped into the surrounding highly dried air used for spinning, with a dew point of $-100^{\circ} \mathrm{C}$. As shown in the precedent section, this dehydration induced a broadening of the peaks corresponding to $\mathrm{P}_{123}$, especially that for the $\mathrm{CH}_{2}-\mathrm{PEO}$ at $3.87 \mathrm{ppm}$. Similarly, ${ }^{13} \mathrm{C}$ resonances of $\mathrm{CH}_{2}-\mathrm{PEO}$ and $\mathrm{CH}_{2}-$ PPO were shifted to higher values by 0.20 and $0.06 \mathrm{ppm}$, respectively (not shown). However, such behavior was neither observed for the E_HT90_dried70_U nor for F_U samples. Indeed, even just after introduction inside the NMR apparatus, no water peak was observed on ${ }^{1} \mathrm{H}$ spectrum and $\mathrm{P}_{123}$ peaks were broad (Figure 8c E_HT90_dried70_U and Figure 8d F_U). We assume that the reproducible spectra recorded with these two samples are due to their partial dehydration, during the EISA treatment itself $\left(220^{\circ} \mathrm{C}, 2.5 \mathrm{~s}\right)$. The peak at $5 \mathrm{ppm}$ observed in the spectra of the two first samples is associated with water interacting with organic molecules when they are trapped inside silica grains. Its absence in the spectra presented Figure 8c and 8dindicates that the PEO chains are dehydrated and have been extracted from the silica walls. 


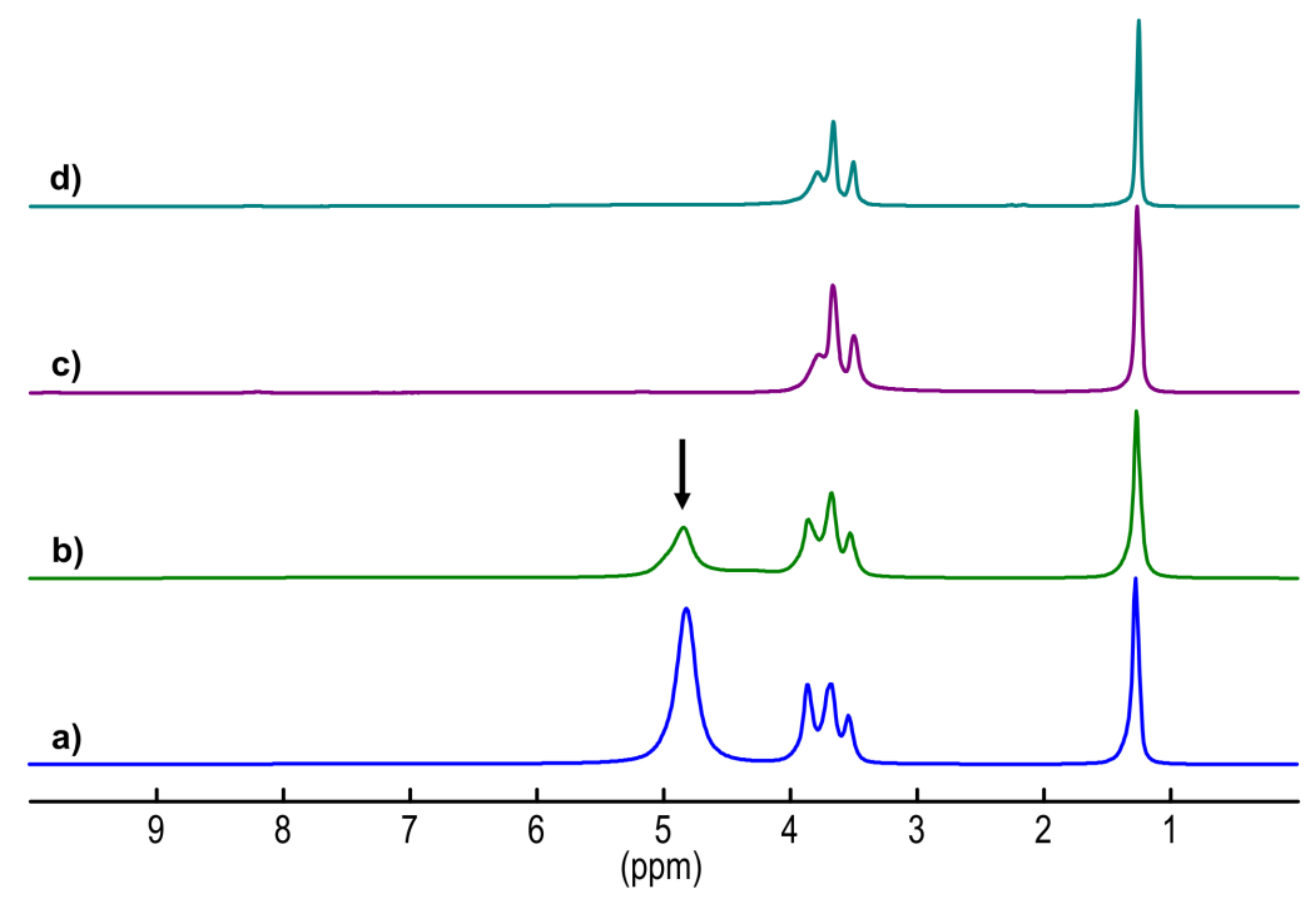

Fig. 8. Hydration of samples. ${ }^{1} \mathrm{H}$ solid-state NMR spectra of (a) B_U at $\mathrm{t}=0$, (b) B_U after $56 \mathrm{~h}$ of sample spinning, (c) E_HT100_U at $\mathrm{t}=$ 0, d) F_U at $\mathrm{t}=0$. Arrow: peak decrease. Parameters: $\left.\left.\left.\mathrm{B}_{0}=16.4 \mathrm{~T}, \mathrm{RD}=10 \mathrm{~s}, \mathrm{LB}=2 \mathrm{~Hz}, \mathrm{a}\right), \mathrm{b}\right) \mathrm{NS}=128, v_{\mathrm{r}}=40 \mathrm{kHz}, \mathrm{c}\right)$, d) NS $=8, v_{\mathrm{r}}=$ $20 \mathrm{kHz}$.

\section{III.3.6. Influence of sample aging time}

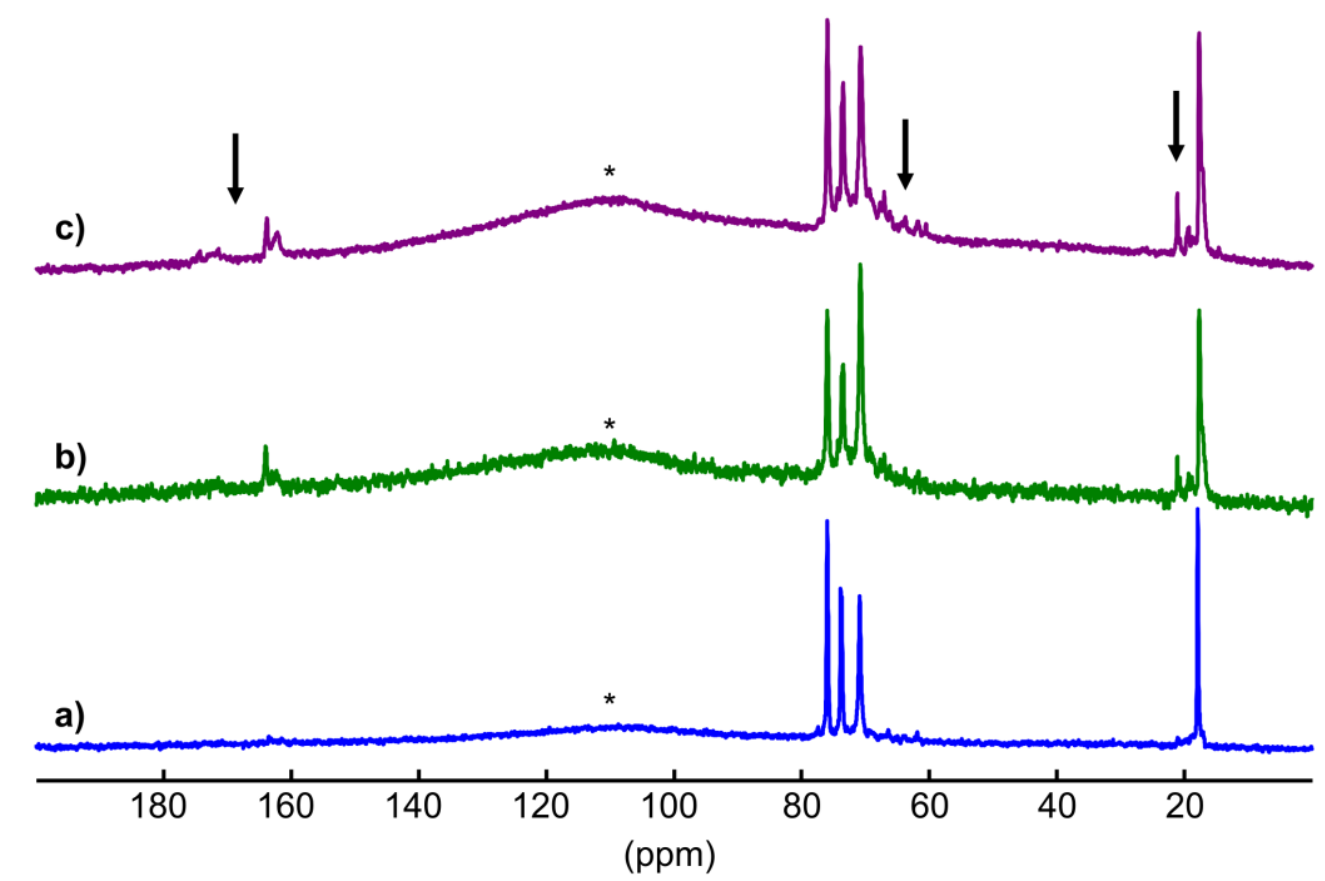

Fig. 9. Sample aging. ${ }^{13} \mathrm{C}$ HPDEC solid-state NMR spectra of A_U: a) after $24 \mathrm{~h}$ aging, b) after 9 months aging, c) after 13 months aging. Parameters: $\mathrm{RD}=3 \mathrm{~s}, \mathrm{LB}=10 \mathrm{~Hz}$, a) NS $\left.\left.=512, v_{\mathrm{r}}=22 \mathrm{kHz}, \mathrm{b}\right) \mathrm{NS}=640, \mathrm{vr}=16 \mathrm{kHz}, \mathrm{c}\right) \mathrm{NS}=4096, v_{\mathrm{r}}=16 \mathrm{kHz}$. ${ }^{\text {probe signal. }}$

Since the hybrids contain traces of chlorine, we have checked the stability of $\mathrm{P}_{123}$ molecules after long time storage of the powder. We have selected to work with the A_U unwashed silica to maximize chlorine contamination and acidic hydrolysis. The HPDEC ${ }^{13} \mathrm{C}$ NMR spectrum obtained just after synthesis, Figure 9a was compared to the spectra acquired after 9 months, Figure $9 \mathrm{~b}$ and 13 months of storage in air at room temperature, Figure 9c, respectively. New signals were detected at 25, 65, 
and $170 \mathrm{ppm}$, as indicated with black arrows. The last signals are due to carbonate groups (as a result of $\mathrm{CO}_{2}$ contamination of basic samples when they are stored in an ambient atmosphere). Other additional signals were complex but they could be attributed to PPO and/or PEO hydrolyzed fragments. For instance, glycol was expected at 63.7 ppm where multiple peaks were visible. The relative proportions of the fragments increase with time.

An enhanced resolution was obtained using a $\left\{{ }^{1} \mathrm{H}\right\}-{ }^{13} \mathrm{C}$ INEPT $2 \mathrm{D}$ experiment after 24 months of aging (Figure 10). While the peaks for $\mathrm{P}_{123}$ were easily identified (in red), confirming the partial integrity of the polymer inside the saved powder, numerous fragments were visible near each peaks (in green and blue). This highlighted a degradation of $\mathrm{P}_{123}$ in the presence of remaining chlorine traces. Both PPO and PEO chains were damaged and submitted to an acidic hydrolysis. The multiplicity of signals demonstrated that fragments could have different sizes and the degradation reactions can occur at various positions inside the polymer molecule, even if some polymer molecules are preserved. In red, the basic attributions described before are confirmed, in particular the association between ${ }^{1} \mathrm{H}$ and ${ }^{13} \mathrm{C}$ nuclei. The presence of 1,2 -ethanediol is demonstrated by the presence of ${ }^{13} \mathrm{C}$ ${ }^{-1} \mathrm{H}$ peaks at 63.71-3.71 and 63.71. 3.17 ppm. There is an interesting new group of ${ }^{1} \mathrm{H}$ at 2 ppm, which corresponds to the ${ }^{13} \mathrm{C}$ signal at $21 \mathrm{ppm}$ and associated with degradation products. We assume that these new peaks areattributed to 3-hydroxypropionic acid, $\mathrm{HO}-\mathrm{CH}_{2}-\mathrm{CH}_{2}-\mathrm{COOH}$ due to a possible carbonylation of $\mathrm{PEG}$ or monomeric 1,2-ethanediol with atmospheric $\mathrm{CO}_{2}$ (or neighboring carbonates dispersed on the silica surface) as can be expected in a very strongly acidic environment (this sample is the only one in which decomposition products have been analyzed). This sample has the highest amount of chlorine $(0.154 \%)$ and it has been stored for a very long time in ambient air. It is important to underline this point since the observed reaction occurred spontaneously and in ambient conditions. Some old references have been devoted to this reaction and this kind of reaction is of fundamental importance for other molecules, e.g., glycerol [38]. This $\left\{{ }^{1} \mathrm{H}\right\}-{ }^{13} \mathrm{C}$ INEPT $2 \mathrm{D}$ solid-state NMR spectrum of A_U after 24 months aging is necessary to demonstrate that native $\mathrm{P}_{123}$ molecules (signals in red), and several organic fragments (shorter chains, in blue and green), can be present if an hybrid powder is stored in air for a long time without precautions, in particular if $\mathrm{O}_{2}$ and $\mathrm{CO}_{2}$ molecules are present in the gas phase and can be dissolved in remaining water.

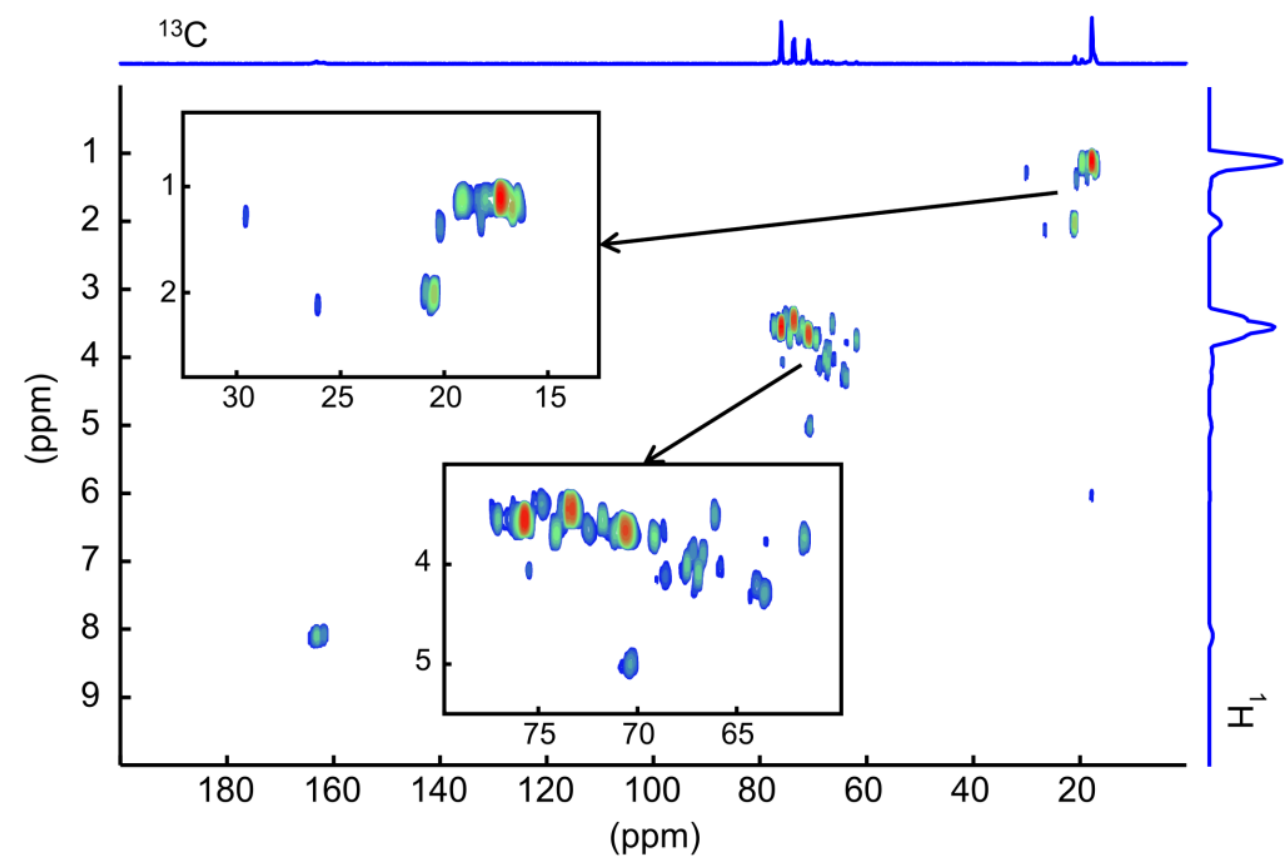

Fig. 10. $\left\{{ }^{1} \mathrm{H}\right\}-{ }^{13} \mathrm{C}$ INEPT 2D solid-state NMR spectrum of A_U after 24 months aging. Top and right) ${ }^{13} \mathrm{C}$ and ${ }^{1} \mathrm{H}$ projections. Parameters: $\mathrm{B}_{0}=16.4 \mathrm{~T}, \mathrm{RD}=1 \mathrm{~s}, \mathrm{NS}=512,96$ slices, $v_{\mathrm{r}}=10 \mathrm{kHz}$. 


\section{III.4. Additional information about calcined samples}

Additional characterizations were made to check if the materials were well ordered and details are summarized in Supplementary Information. Only a summary table allowing a direct comparison of textural properties is inserted here (Table 3) and summarizes $\mathrm{N}_{2}$ sorption results (specific surface area, porous volume and main diameter of mesopores) and SAXS measurements (unit-cell parameter) and an evaluation of $\mathrm{Cl}^{-}$content in selected samples. As expected, a HT yields to an increase of mesopores diameter and a decrease of $\mathrm{Cl}^{-}$content corresponding well to a situation in which the PEO chains are expulsed from silica walls and participate to the core of the cylindrical micelles and the $\mathrm{P}_{123}$ molecules are eroded. It is interesting to notice that the evolution of the detected microporous volume nicely agrees with the information provided by NMR and a progressive decrease wasalso observed with HT. The sample obtained by flash drying is peculiar since its NMR spectrum indicates a main location of the PEO chains outside the silica walls and the detected micropores are then textural (within silica grains) more than structural. It is not the case when hybrid was prepared by precipitation using TEOS, $\mathrm{P}_{123}$ and concentrated $\mathrm{HCl}$ aqueous solution (2M). In that case, a corona in which PEO chains, water and silica precursors are interacting was evidenced by SAXS [38] and carefully studied by $\mathrm{N}_{2}$ sorption [39]. Micropores have been shown to connect adjacent mesopores, consistent with replicationwith carbon [40]. The obtained metallic or oxides nanowires formed inside mesopores stay connected and attached. The optimal porous volume is obtained with the B_HT130_C sample synthesized with $\mathrm{HCl} 1.6 \mathrm{~mol} . \mathrm{L}^{-1}$. In this sample, that has been washed with $2 \mathrm{~L}$ of water, only $347 \mathrm{ppm}$ of chlorine remains. Surprisingly, no pores remain if the same hybrid is first submitted to a drying step at $70^{\circ} \mathrm{C}$ for $26 \mathrm{~h}$ before calcination. The specific surface area of a sample precipited in $\mathrm{HCl} 1.9$ mol.L $\mathrm{L}^{-1}$ was strongly affected by storage time in air and it decreased by more than $100 \mathrm{~m}^{2} . \mathrm{g}^{-1}$ for calcinations performed after 1 and 13 months of storage.

Information concerning IR measurements performed to study and quantify silanols groups and water molecules adsorbed in calcined samples stored in air are also summarized in Supplementary Information. A larger microporous volume is systematically associated with a larger fraction of isolated and/or gemini silanol groups. A special attention to the location of isolated/gemini groups inside the disordered micropores in silica walls and not inside mesopores or outside silica grains is justified. With three samples prepared by precipitation in $\mathrm{HCl} 1.9 \mathrm{~mol} . \mathrm{L}^{-1}$, two types of water molecules are associated with vibrations at $1936-1926$ and $1897-1888 \mathrm{~nm}$. These two vibrations are shifting regularly toward lower values between a A1_C sample without HT, a A2_C with applied HT at $90^{\circ} \mathrm{C}$ for $24 \mathrm{~h}$ and a A3_C sample with HT at $130^{\circ} \mathrm{C}$ for $24 \mathrm{~h}$. Their relative integrated intensities are changing from 55.9/44.1 to 83.5/16.5 \%. The second signal is then decreasing as a function of the microporous volume (Table 3 ) and this allowed us to associate them to water molecules located in micropores.

\section{Conclusions and perspectives}

Hybrid silicas have been obtained by both precipitation and by evaporation using the same $\mathrm{P}_{123}$ triblock copolymers as template. A detailed NMR characterization of the organic template inside mesostructured phases was conducted in order to investigate their mobility, conformations and stability. Two major effects of synthetic procedure and post treatments (or storage time) were evidenced. Firstly, minor aspects:

- Some copolymer acidic hydrolysis was observed for all samples having been heated during synthesis (that is, hydrothermal treatment for precipitation experiments, or drying temperature for spray drying experiments).

- Some PEO fragments are eliminated with the washing treatment of precipitated powders.

- 1,2-ethanediol and peroxide traces associated with the copolymer decomposition are identified by NMR. 
- The temperature of the heat treatment applied during hydrothermal synthesis is directly correlated with the remaining $\mathrm{EO} /(\mathrm{EO}+\mathrm{PO}) \mathrm{wt} \%$.

The strongest decomposition was observed with a precipitated sample prepared in $\mathrm{HCl} 1.8-2 \mathrm{M}$ and submitted to a hydrothermal treatment of $130^{\circ} \mathrm{C}$ for 24 hours (the $\mathrm{EO} /(\mathrm{EO}+\mathrm{PO})$ ratio decreased by $50 \%$ as compared to fresh sample). Nevertheless, this sample presents an order between mesopores of very good quality (See Supplementary Information 4-5). As a consequence, the degradation observed does not affect the structuration mechanism itself and/or takes place after the cooperative self-assembly between organic and inorganic precursors.

A non-calcined hybrid stored for 13 months in air before calcination has lost a significant part of its surface area (-21\%) and pore volume $(-36 \%)$. Such a silica porous texture evolution is clearly a potential problem for applications requiring long term storage and stability of products.

Secondly, a major observation, the NMR study of polymer chains mobility confirms the dehydration and retraction of PEO chains upon temperature increase. We proved for the first time that this effect, now well known for precipitated SBA-15 materials, also occur for spray-dried samples.

\section{AUTHORS INFORMATIONS}

\section{Corresponding Author}

BD (brindusa.dragoi@yahoo.com), GL (guillaume.laurent@sorbonne-universite.fr), TB (taissire.benamor@gmail.com).

\section{Author Contributions}

The manuscript was written through contributions of all authors. All authors have given approval to the final version of the manuscript. "The authors declare non conflict of interest"

\section{ACKNOWLEDGMENT}

Paris-Ile-de-France - SESAME program is acknowledged for financial support (700 MHz spectrometer). B. Dragoi acknowledges the project PERFORM-ERA "Post- doctoral Performance for Integration in the European Research Area" (ID-57649), financed by the European Social Fund and the Romanian Government.

\section{REFERENCES}

1. Kerkhofs S, Saidi F, Vandervoort N, Van den Mooter G, Martineau C, Taulelle F, Martens J (2015) Silica Capsules Enclosing P 123 Triblock Copolymer Micelles for Flurbiprofen Storage and Release. J Mat Chem B 3:3054-3061

2. Taguchi A, Schüth F (2005) Ordered Mesoporous Materials in Catalysis. Microp Mesop Mat77: 1-45

3. Zhao D, Feng J, Huo Q, Melosh N, Fredrickson GH, Chmelka BF, Stucky GD (1998) Triblock copolymer synthesis of mesoporous silica with periodic 50 to 300 Å pores. Science 279 (5350) 548-552

4. Ruthstein S, Schmidt J, Kesselman E, Talmon Y, Goldfarb D (2006) Resolving Intermediate Solution Structures During the Formation of Mesoporous SBA-15. J Am Chem Soc. 128: 3366-3374

5. Khodakov A, Zholobenko VL, Impéror-Clerc M, Durand D (2005) Characterization of the Initial Stages of SBA-15 Synthesis by in Situ Time-Resolved Small-Angle X-ray Scattering. J Phys Chem B 109 (48): 22780-22790.

6. Firouzi A, Atef F, Oertli AG, Stucky GD, Chmelka, BF (1997) Alkaline Lyotropic Silicate-Surfactant Liquid Crystals. J Am Chem Soc 119 (15): 3596-3610 
7. Yang CM, Zibrowius B, Schmidt W, Schüth F (2004) Stepwise Removal of the Copolymer Template from Mesopores and Micropores in SBA-15. Chem Mater16 (15): 2918-2925

8. Bae YK, Han OH (2008) Solid-State NMR Study on the Structure and Dynamics of Triblock Copolymer P123 Remaining in SBA-15 after Solvent Washing. Bull Korean Chem Soc 29 (5): 911-912

9. Zhang Z, Yin J, Heeres HJ, Melián-Cabrera I (2013) Thermal Detemplation of SBA-15 mesophases. Effect of the Activation Protocol on the Framework Contraction.Microp Mesop Mat 176: 103-111

10. Manet S, Schmitt J, Impéror-Clerc M, Zholobenko V, Durand D, Oliveira CLP, Pedersen JS, Gervais C, Baccile N, Babonneau F, Grillo, I, Meneau, F, Rochas, C. (2011) Kinetics of the Formation of 2D-Hexagonal Silica Nanostructured Materials by Nonionic Block Copolymer Templating in Solution. J Phys Chem B 115 (39): 11330-11344

11. Manet S, Lecchi A, Impéror-Clerc M, Zholobenko V, Durand D, Oliveira CLP, Pedersen JS, Grillo I, Meneau F, Rochas C (2011) Structure of Micelles of a Nonionic Block Copolymer Determined by SANS and SAXS. J. Phys. Chem. B115 (39): 11318-11329

12. Sayari A, Han BH, Yang Y (2004) Simple Synthesis Route to Monodispersed SBA-15 Silica Rods. J Am Chem Soc 126 (44): 14348 14349.

13. Yu K, Smarsly B, Brinker CJ (2003) Self-Assembly and Characterization of Mesostructured Silica Films with a 3D Arrangement of Isolated Spherical Mesopores. Adv Funct Mater 13 (1): 47-52.

14. Boissière C, Grosso D, Amenitsch H, Gibaud A, Coupé A, Baccile N, Sanchez C (2003) First in-situ SAXS studies of the mesostructuration of spherical silica and titania particles during spray-drying process, Chem Commun: 2798-2799.

15. Boissiere C., Grosso D, Chamonnot A, Nicole L, Sanchez C (2011) Aerosol route to functional nanostructured inorganic and hybrids porous materials, Adv. Mater. 23, 599-623.

16. Yu GE, Altinok H, Nixon S.K., Booth C, Alexandridis, P, Halton TA (1997) Self -Association Properties of Oxyethylene/Oxypropylene/Oxyethylene Triblock Copolymers F88, Eur. Polym. 33 (5) 673-677.

17. Christy AA (2010) New Insights into the Surface Functionalities and Adsorption Evolution of Water Molecules on Silica Gel Surface: A Study by Second Derivative Near Infrared Spectroscopy. Vib Spectrosc 54 (1): 42-49.

18. Workman JJ (1996) Interpretative Spectroscopy for Near Infrared. Appl Spectrosc Rev31 (3): 251-320.

19. GenkawaT, Watari M, NishiiT, Suzuki M, Ozaki Y (2013) Two-Dimensional Heterospectral Correlation Analysis of Water and Liquid Oleic Acid using an Online Near-Infrared/Mid-Infrared Dual-Region Spectrometer. Appl. Spectrosc. 67 (7): $724-730$.

20. Hourant P, Baeten V, Morales MT, Meurens M, Aparicio R (2000) Oil and Fat Classification by Selected Bands of Near-Infrared Spectroscopy. Appl. Spectrosc 54(8): 1168-1174.

21. Omar AF, Atan H, MatJafri MZ (2012) NIR Spectroscopic Properties of Aqueous Acids Solutions. Molecules 17 (6): 7440

22. Schmidt P, Badou A, Fröhlich F (2011) Detailed FT Near-Infrared Study of the Behaviour of Water and Hydroxyl in Sedimentary LengthFast Chalcedony, $\mathrm{SiO}_{2}$ upon Heat Treatment. SpectroChimActaA81 (1): 552-559.

23. Schmidt P, Masses, L.G, Slodczyk A, Le Bourhis E, Perrenoud C, Livage J, Fröhlich F (2012) Crystallographic and structural transformations of sedimentary chalcedony in flint upon heat treatment. J. Archeol. Sci. 39(1): 135-144.

24. Schmidt P, Lauer C, Buck G, Miller CE, Nickel KG (2017) Detailed Near-Infrared Study of the 'Water'-Related Transformations in Silica Upon Heat Treatment. Phys Chem Miner 44 (1): 21-31.

25. Langer K, FlörkeOW (1974) Near Infrared Absorption Spectra (4000-9000 $\left.\mathrm{cm}^{-1}\right)$ of Opals and the Role "Water" in $\mathrm{These}^{\mathrm{SiO}}{ }_{2} \cdot \mathrm{nH} \mathrm{H}_{2} \mathrm{O}$ Minerals. Fortschritte. Mineral52, 17-51. 
26. Fulmer GR, Miller AJM, Sherden NH, Gottlieb HE, Nudelman E, Stoltz BM, Bercaw JE, Goldberg KI (2010) NMR Chemical Shifts of Trace Impurities: Common Laboratory Solvents, Organics, and Gases in Deuterated Solvents Relevant to the Organometallic Chemist. Organometallics 29 (9) 2176-2179.

27. Harris RK, Becker ED, Cabral de Menezes SM, Granger P, Hoffman RE, ZilmKW (2008) Further Conventions for NMR Shielding and Chemical Shifts (IUPAC Recommendations 2008) Solid State Nucl Mag Res 33(3) 41-56.

28. Elena B,, Lesage A, Steuernagel S, Böckmann A, Emsley L (2005) Proton to Carbon-13 INEPT in Solid-State NMR Spectroscopy J Am Chem Soc 127 (49) 17296-17302.

29. Sørensen OW, Ernst RR (1969) Elimination of spectral distortion in polarization transfer experiments. Improvements and comparison of techniques, J. Magn. Reson 51 (3) 477-489.

30. Bjoerling M, Karlstroem G, Linse P (1991) Conformational Adaptation of Poly (Ethylene Oxide): A ${ }^{13}$ C Carbon NMR Study. J Phys Chem (95) 17, 6706-6709.

31. Sasanuma Y (1995) Conformational Analysis of Poly (Propylene Oxide) and Its Model Compound 1,2-Dimethoxypropane. Macromolecules, 28: 8629-8638.

32. Ma J, Guo C, Tang Y, Wang J, Zheng L, Liang X, Chen S, Liu H (2006) Microenvironmental and Conformational Structure of Triblock Copolymers in Aqueous Solution by ${ }^{1} \mathrm{H}$ and ${ }^{13} \mathrm{C}$ NMR Spectroscopy J Colloid Interf Sci 299 (2) 953-961

33. Wurtz P, Permi P, Nielsen NC, Sorensen OW (2008) Clean HMBC: Suppression of strong-coupling induced artifacts in HMBC. J Magn Reson 194 (1): 89-98.

34. Mathias A, Mellor N (1966) Analysis of Alkylene Oxide Polymers by Nuclear Magnetic Resonance Spectrometry and by Gas-Liquid Chromatography Anal Chem 38 (3) 472-477.

35. Randall Holmes-Farley S, Reamey RH, Mac Carthy JT, Deutch J, Whitesides GM (1985) Acid-base behavior of carboxylic acid groups covalently attached at the surface of polyethylene: The usefulness of contact angle in following the ionization of surface functionality.Langmuir 1 (6): 725-740.

36. Liu CC, Marcel GE (1996) The fumed silica surface, a study by NMR. J Am Chem Soc 118: 5103-5119.

37. Liu J, LiY, Zhang J, He D (2016) Glycerol carbonylation with $\mathrm{CO}_{2}$ to glycerol carbonate over $\mathrm{CeO}_{2}$ catalyst and the influence of $\mathrm{CeO}_{2}$ preparation methods and reaction parameters. Appl Catal A: General 513: 9-18

38. Imperor-Clerc M, Davidson P, Davidson A (2000) Existence of a microporous corona around the mesopores of SBA-15 silica materials templated by triblock copolymers. J Am Chem Soc 122:11925-11933

39. Galarneau A, Cambon H, Di Renzo F, Fajula F (2001) True microporosity and surface area of mesoporous SBA- 15 silicas as a function of synthesis temperature. Langmuir 17 (26) 8328-8335.

40. Parmentier J, Saadhallah S, Reda M, Gibot L, Roux C, Vidal C, Vix-Guter C, Patarin J (2004) New carbons with controlled nanoporosity obtained by nanocasting using a SBA-15 mesoporous silica host matrix and different preparation routes. J. Phys. Chem. Solids 65 (2-3) 139-146. 


\title{
Supplementary information
}

\section{Stability and degradation of $\mathrm{PEO}_{20} \mathrm{PPO}_{70} \mathrm{PEO}_{20}$ triblock copol- ymers, in mesostructured silica}

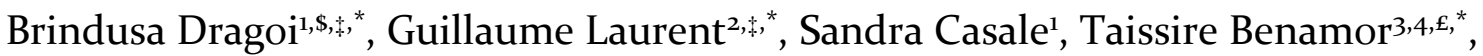 \\ Bénédicte Lebeau ${ }^{3,4}$, Cédric Boissière², François Ribot ${ }^{2}$, Mohamed Selmane ${ }^{5}$, \\ Patrick Schmidt ${ }^{6}$, David Kreher ${ }^{7}$, Anne Davidson ${ }^{1, \$}$
}

\footnotetext{
${ }^{1}$ Sorbonne Université, CNRS, Laboratoire de Réactivité de Surface, 4 Place Jussieu, F75005 Paris, France

${ }^{2}$ Sorbonne Université, CNRS, Laboratoire de Chimie de la Matière Condensée de Paris, 4 place Jussieu, F75005 Paris, France

${ }^{3}$ Université de Haute Alsace, CNRS, Institut de Science des Matériaux de Mulhouse, 3bis rue A. Werner, F68100 Mulhouse, France

${ }^{4}$ Université de Strasbourg, France

${ }^{5}$ Sorbonne Université, CNRS, Institut des Matériaux de Paris Centre, 4 place Jussieu, F75005 Paris, France

${ }^{6}$ Eberhard Karls University of Tübingen, Department of Geosciences, Applied Mineralogy, Wilhelmstraße 56, 72074 Tübingen, Germany

${ }^{7}$ Sorbonne Université, CNRS, Laboratoire de Chimie des Polymères, 4 Place Jussieu, F75005 Paris, France

${ }^{\text {SC}}$ Current address : Alexandru Ioan Cuza University of Iasi, $11^{\text {th }}$ Carol I Boulevard, 700506 Iasi, Romania

${ }^{\text {f}}$ Current address :Technopole de Borj-Cédria, Centre de Recherches et des Technologies des Eaux, Route touristique de Soliman, BP 273-8020 Soliman, Tunisia
}

$\ddagger$ These authors contributed equally

*Corresponding authors 
Table of content:

SI1. Hybrids preparation

SI2. Grains shapes of selected samples as studied by Scanning Electron Microscopy, SEM and by Transmission Electron Microscopy, TEM

SI3. Order in hybrids and in calcined silica grains by Small Angle X-ray Scattering

SI4. Surface of calcined silicas, quantification of several kinds of silanol and water groups

SI5. $\mathrm{N}_{2}$ sorption on two silicas 


\section{SI1. Hybrids preparation}

The three first hybrids have been prepared for a highly acidic $\mathrm{pH}=0$ aqueous solution and in the experimental conditions recommended in the publication of Zhao et al.8, with a constant $\mathrm{P}_{123} / \mathrm{TEOS}$ molar ratio of 60-62.5. Overall proportions of reagents were multiplied by 18 to obtain more than $50 \mathrm{~g}$ of hybrid silica with reasonably homogeneous grain sizes and shapes. Details about the used experimental parameters have been summarized in Table 1 in main text. The first hybrid was prepared by diluting $72.7 \mathrm{~g}$ of $\mathrm{P}_{123}$ in an acidic solution at pH 0 made by mixing $318.2 \mathrm{~g} \mathrm{HCl}$ (commercial, 37\% in weight) and $1832.0 \mathrm{~g}$ of distilled $\mathrm{H} 2 \mathrm{O}$ at $35^{\circ} \mathrm{C}$. After complete dilution, $170 \mathrm{ml}$ of TEOS were added as regularly as possible

(turbo-pump, $2 \mathrm{~mL} \cdot \mathrm{min}^{-1}$ ). Stirring was stopped at the end of the TEOS addition and the temperature of the synthesis step, called "aging", was maintained at $35^{\circ} \mathrm{C}$ for $24 \mathrm{~h}$. After aging, silica grains and synthesis liquor were separated into two fractions, one being directly filtrated (no washing, no drying, labeled A_U, U symbol for uncalcined). An identical hybrid was prepared in similar conditions, the powder being recovered by filtration on Buchner and washed with 3L of water. This washed hybrid is called B_U. The unwashed fraction was submitted to a condensation hydrothermal treatment at 90 or $130^{\circ} \mathrm{C}$ for $24 \mathrm{~h}(380$ $\mathrm{ml}$, Teflon-lined stainless steel autoclave, no stirring, powder and mother liquor transferred into autoclaves, 50 to $200 \mathrm{ml}$ ) before filtration on Buchner and washing. We have found necessary to wash $50 \mathrm{~g}$ of hybrid silica with 3L of water. One of these samples is labelled B_HT130_U. In this expression, 130 corresponds to the temperature of the applied hydrothermal treatment, HT, for $24 \mathrm{~h}$. To test reproducibility and sensitivity to small changes in experimental conditions, dilution and potential leak of the used autoclaves, similar synthesis have been reproduced 2 times.

Four samples have been prepared with other acidic solutions at pH 0.4, two with $2096 \mathrm{ml}$ of water acidified by $54 \mathrm{ml}$ of $\mathrm{HCl}(37 \%)$, C_U, no HT, and C_HT130_U, HT and two corresponding to a half dilution using the same amount of $\mathrm{P}_{123}$ and TEOS diluted in $1321 \mathrm{ml}$ of water acidified by $34 \mathrm{ml}$ of $\mathrm{HCl}(12 \mathrm{M}$, 37\%), D_U, no HT and D_HT130_U, washed and HT. The four powders have been recovered by filtration and washed with water, 3L. Two other samples, called E_HT90_dried70_U and E_HT90_dried70_C were synthesized in $\mathrm{HCl} 0.3 \mathrm{M}$ with a first aging at $28^{\circ} \mathrm{C}$ for $48 \mathrm{~h}$ followed by a hydrothermal treatment at $90^{\circ} \mathrm{C}$ of $24 \mathrm{~h}$, washing with distilled water and drying at $70^{\circ} \mathrm{C}$ in air. A constant stirring was kept 
during the aging step, to obtain specifically attached silica grains forming a double gyroidal structure. Another organic-inorganic hybrid was prepared by evaporation induced self-assembly (EISA). In that case, the condensation of inorganic species occured in suspended aqueous droplets. Compared to precipitation, as all non-volatile components are maintained into the powder, no excess of $\mathrm{P}_{123}$ copolymer is necessary. Secondly, as the solution must be stable a time long enough for performing the spray production (at least one hour), the $\mathrm{pH}$ of the mother solution is increased up to 2, to allow the hydrolysis of TEOS but avoiding the extensive and very fast condensation of the silica network that is observed at low $\mathrm{pH}$. In this case, both the condensation of silicate oligomers and the formation of $\mathrm{P}_{123}$ micelles are promoted by the rapid increase of concentration of the chemical components inside water droplets due to an evaporation in hot air $\left(220^{\circ} \mathrm{C}\right)$. This last step is performed in a couple of seconds with a Buchi B290 Mini Spray Drier. 


\section{SI2. Grains shapes of selected samples as studied by Scanning Electron Microscopy (SEM)}

Size and shape of hybrid silica grains were evaluated by SEM. The used apparatus, a SU-70 HITACHI

SEM, is equipped with an SDD detector of $50 \mathrm{~mm}^{2}$ and a Field Emission Gun accessory (FEG) recorded with a Field Emission Gun (FEG). This accessory is necessary to avoid the usual deposition of an electron conducting material by carbonation or metallisation on the studied samples. Micrographs were measured with an accelerating voltage of $1 \mathrm{kV}$. Chemical homogeneity level was characterized using X-ray Energydispersive Spectroscopy, EDS with an Oxford X-MAX apparatus.

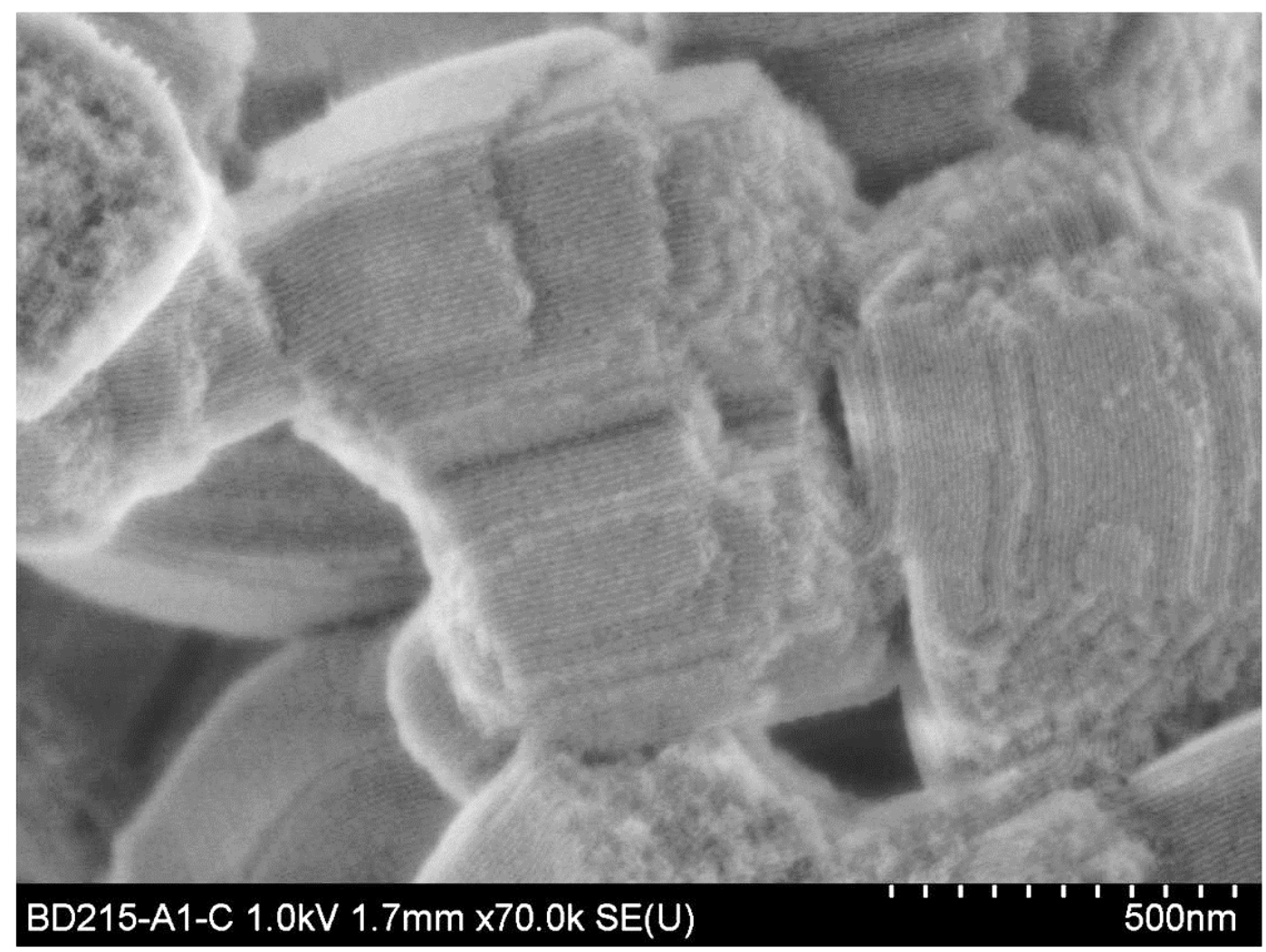

Fig. 11. SEM micrograph enlargement of a grain of $\mathrm{B}_{-} \mathrm{C}$ (calcined at $500^{\circ} \mathrm{C}$, rate of $2^{\circ} \mathrm{C}$ by min and kept $6 \mathrm{~h}$ ). The presented grain is a short one, a defect in a synthesis performed with $\mathrm{HCl} 2 \mathrm{~mol} \cdot \mathrm{L}^{-1}$. The main axis of mesopores is running parallel to its shorter axis. Several layers of silica, grown concentrically are observed, indicating non-homogeneities in the rate of addition of TEOS during the synthesis. Structural defects are also apparent (missing silica wall, darker aspect). Some disorder is detected on flat surfaces. 
Differences in calcined silica grains sizes and shapes were observed on SEM micrographs (Figure 12). The grains can be either isolated or attached and forming a double gyroid structure, depending mainly upon the $\mathrm{pH}$ in solution and also on stirring conditions upon aging. In the used experimental conditions, at $35^{\circ} \mathrm{C}$, isolated grains, Figure 12 (a) and (b) are formed if stirring conditions are stopped during the aging step, as indicated first by Sayari et al. [1]. With more HCl, sample B_HT130_U (pH 0.0, HCl concentration 2 mol. L-1), the silica grains are more elongated, with a main elongation axis parallel to their mesopores. These shapes differences, associated with $\mathrm{pH}$, are consistent with literature data [2].

A micrograph relative to fragments of gyroidal-chains of attached grains generated by keeping agitation during the maturation step, sample E-dried70_U (aging at $28^{\circ} \mathrm{C}$ for $24 \mathrm{~h}, \mathrm{HT}$ at $90^{\circ} \mathrm{C}$ for $24 \mathrm{~h}$, dried at $70^{\circ} \mathrm{C}$ for $24 \mathrm{~h}$ after recovering by Büchner (paper filtration) is presented for comparison in Figure 12(c).

Finally, the sample F_U presented in Figure 12(d) has been obtained by flash drying, is composed of spherical silica particles with a broad size distribution range (100 nm to several microns, closed or not). This morphology and a large size distribution are direct consequences of the spray drying process in itself by which the distribution in size of spherical droplets of solvent is, in general, large. 

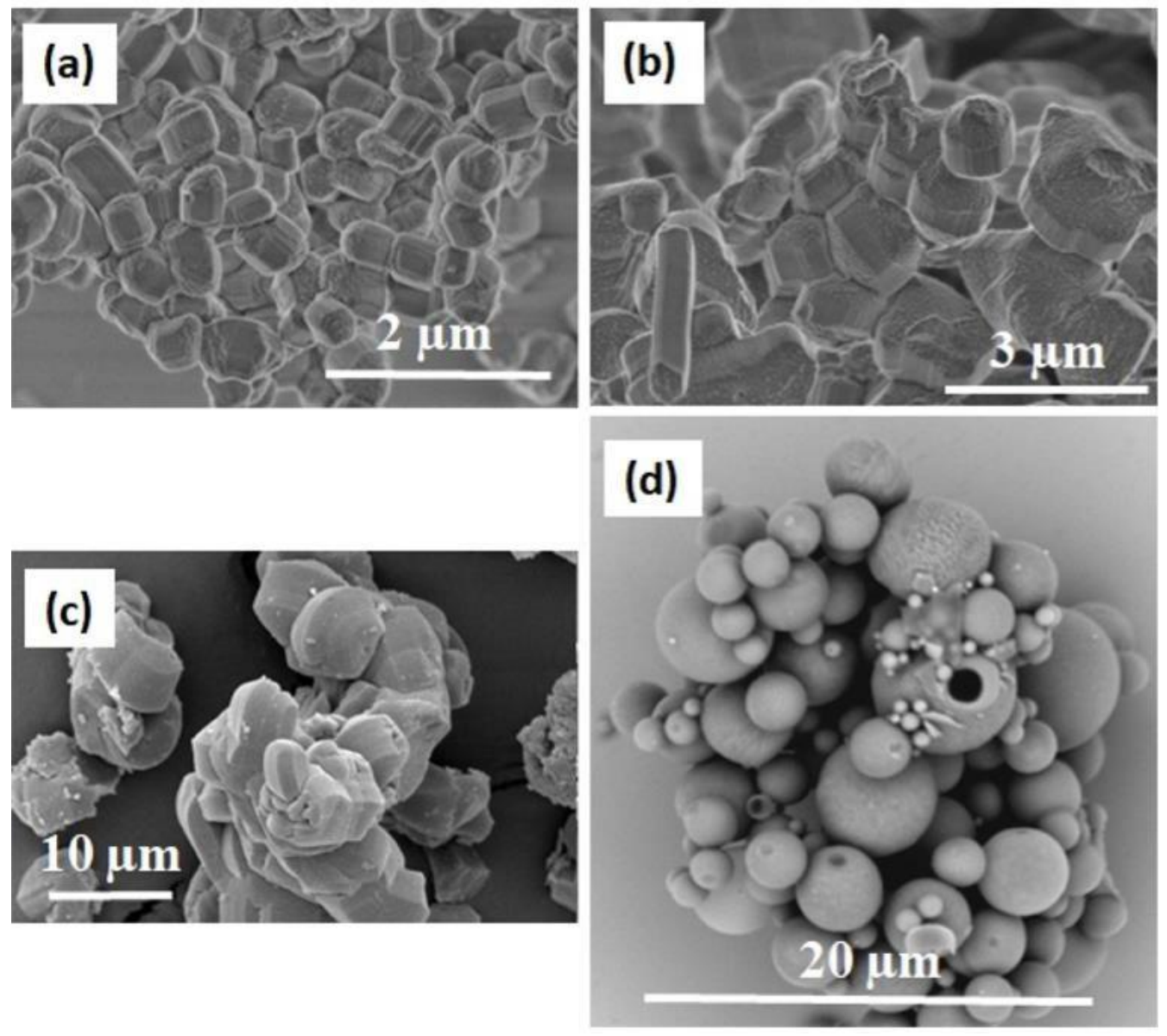

Fig. 12. Representative SEM micrographs of precipitated silica hybrids: isolated silica grains obtained at high acidity (a) and low acidity (b), both uncalcined, double gyroidal structure associated with uncalcined E-HT90_dried70_U (c) and a sample F_U obtained by Evaporation Induced Self Assembly (d).

To describe the homogeneity of the hybrid samples, four micrographs have been recorded with a FEGSEM and are presented in Figure 13. Figure 13 (a) and (b) have been obtained with the same silica prepared at pH 0 (B_U uncalcined type) with a hydrothermal treatment performed at $130^{\circ} \mathrm{C}$ for $24 \mathrm{~h}$ into two distinct autoclaves of $75 \mathrm{ml}$. The sizes and shapes of the hybrid grains in the two micrographs are similar, indicating that the preparation is reasonably reproducible. The micrographs in Figures 13 (c) and (d) are relative to the B_C (fraction without HT) and B_HT130_C (fraction submitted to the HT at $130^{\circ} \mathrm{C}$ $24 \mathrm{~h})$, both calcined at $500^{\circ} \mathrm{C}\left(2^{\circ} \mathrm{C}\right.$ by $\left.\min , 6 \mathrm{~h}\right)$. 

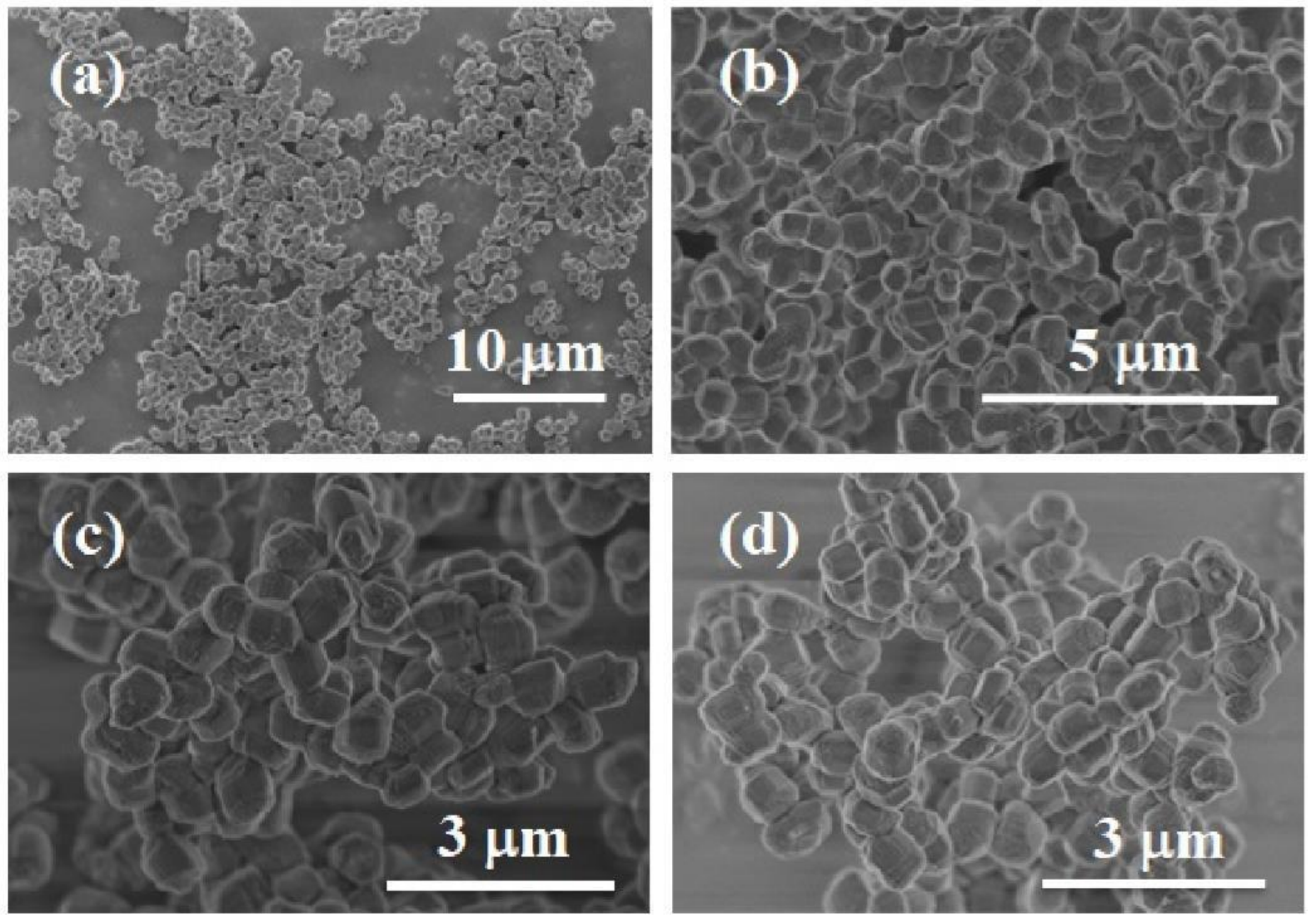

Fig. 13. Reproducibility tests, comparison between FEG-SEM micrographs of: (a), (b) hybrid B_U, same synthesis HT at $130^{\circ} \mathrm{C} 24 \mathrm{~h}$, separated into two distinct autoclaves of $75 \mathrm{ml}$, (c) B_C, (d) B_HT130_C calcined samples. 


\section{SI3. Order in hybrids and in calcined silica grains by Small Angle X-ray Scattering}

Order in hybrids and in calcined silica grains by Small Angle X-ray Scattering Order between parallel mesopores was checked by SAXS (within the range $0.5-5^{\circ}$ ) on a Rigaku S-MAX 3000 diffractometer using a $\mathrm{Cu} \mathrm{Ka}$ excitation source, working at $\lambda=0.15406 \mathrm{~nm}$. Measurements in

Figures 14 were made in transmission, the hybrid powder being manually packed in borosilicate glass capillaries of $1 \mathrm{~mm}$ in diameter (to keep a reasonable transmitted X-ray flux after the powder and keep a limited absorption). Because of the used capillaries and manual packing, it was difficult to estimate precisely peaks relative intensities. After calcination, there is a strong difference between the electronic density contrast existing inside the pores and inside the silica walls. In Figure 14, the X-ray diffraction measurements are presented in linear $\left(q=2^{*} \pi / d\right)$ versus $\log 10$ (intensity). The performed mathematical treatment is aimed at increasing the intensity of the smallest diffractions.

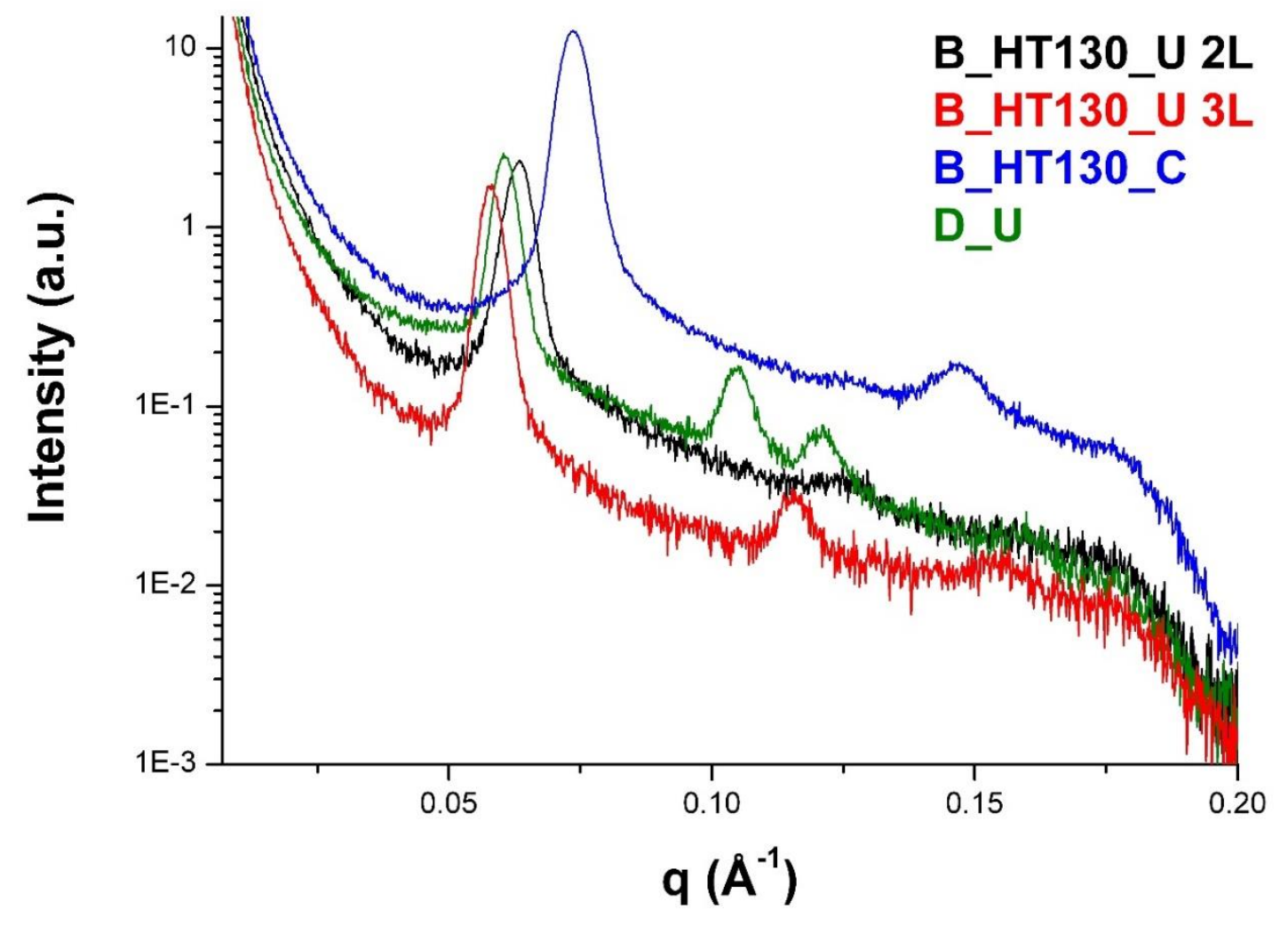

Fig. 14. SAXS measurements 
SAXS measurements have been performed on one D sample (synthesis made with $71.61 \mathrm{~g} \mathrm{P} 123,34 \mathrm{~mL}$ of $\mathrm{HCl} 37 \%, 1863 \mathrm{~mL}$ of water and $167.28 \mathrm{~mL}$ of TEOS) and three B (synthesis made with $71.61 \mathrm{~g} \mathrm{P}_{123}$, $287 \mathrm{~mL}$ of $\mathrm{HCl} 37 \%, 1863 \mathrm{~mL}$ water and $167.28 \mathrm{~mL}$ of TEOS) obtained after three distinct treatments:

- B_HT130_U 2L, submitted to a HT at $130^{\circ} \mathrm{C}, 24 \mathrm{~h}$, recovered by filtration on paper and washed with $2 \mathrm{~L}$ of distilled water

- B_HT130_U 3L, submitted to a HT at $130^{\circ} \mathrm{C}, 24 \mathrm{~h}$, recovered by filtration on paper and washed with $3 \mathrm{~L}$ of distilled water

- B_C HT130_C calcined at $500^{\circ} \mathrm{C}$ in $\operatorname{air}\left(\right.$ rate of $2^{\circ} \mathrm{C}$ by min) then $6 \mathrm{~h}$

Three clear diffraction peaks indexed by h, k, l: (100), (110) and (200) are observed for B_HT130_C calcined sample, prepared at $\mathrm{pH}$ 0. These three peaks correspond to a unit-cell in the p6mm space-group and to the well-ordered 2D hexagonal structure formed by the pores, as reported for calcined SBA-15 in initial publications [2]. Only very weak (110) and (200) diffraction peaks are observed for the hybrid D_U synthesized in less acidic conditions, here a $\mathrm{HCl}$ of concentration 0.6 to $0.3 \mathrm{~mol}$. $\mathrm{L}^{-1}$. A clear sensitivity to washing with water is detected by comparing the two diffractions recorded B_HT130_U washed with 2L of water and B_HT130_U washed with 3L of water: with the second sample, only two diffraction peaks are detected at $\mathrm{q}=0.57$ and $1.18 \mathrm{~nm}^{-1}$ and can be associated to a lamellar phase.

Unit-cell parameter, a, as obtained by FullProf program of simulation of the first diffraction peak, indexed (100) and associated with the reticular distance $d_{100}$ are given in Table 2. 


\section{SI4. Surface of calcined silicas, as studied by NIR and quantification of several kinds of silanol groups}

Concerning the NIR-bands attributed to water and surface silanol Si-OH groups in calcined samples, recent references on crystalline hydrated silica (natural chalcedony silica) [3,4], on hydrated opal amorphous silica [5, 6] and on NIR spectra of silica gels [7] are used as references. Three types of silanol groups and two types of water molecules are considered.For their quantification, we used the protocol detailed elsewhere [8].

Calcined hybrids of the SBA-15 family can have very different surface states and then significantly different hydrophilic properties and affinity for water adsorption. We have integrated two NIR peaks, one near $2000 \mathrm{~nm}$ (water) and a second at $1450 \mathrm{~nm}$ (silanols). A narrow first component with a Lorentzian symmetrical profile corresponds to poorly bound water molecules whereas a much broader peak with a strong Gaussian profile is associated with water molecules experiencing strong H-bonds. The prepared calcined samples, stored in closed vials and at room temperature, contain then spontaneously two types of water molecules. The existence of two types of water molecules, one strongly H-bound and the second only weakly H-bound is observed in all samples and has also been reported for NIR measurements performed on pure water. In our spectra, the two observed spectral components are centered at 1894 and $1935 \mathrm{~nm}$. The first component of the $\mathrm{Si}-\mathrm{OH}$ band near $1894 \mathrm{~nm}$ corresponds to isolated and/or gemini silanols (two $\mathrm{OH}$ on the same Si-atom) that do not interact with others silanol groups and/or with water molecules. Other Si-OH groups experiencing multiple Hbonds (neighbors or linked to water molecules) give rise to the much broader $1935 \mathrm{~nm}$ component of Gaussian shape that is shifted to longer wavelengths. The proposed spectroscopic quantifications are summarized in Table SI1.

Even with now established preparation methods, calcined hybrids of the SBA-15 family can have very different surface states and significantly different hydrophilic properties, affinity for water adsorption. To obtain information on that point, we have looked at two NIR signals located respectively near $2000 \mathrm{~nm}$ (water, elongation mode) and $1500 \mathrm{~nm}$ (silanols, bending of Si-O-H groups). Quantifications were made by their integration using the technique described by one of us [8] and are summarized in Table SI1. The water band can be decomposed into a narrow first component with a symmetrical Lorentzian profile that corresponds to poorly bound water molecules W1 and a much broader component with a Gaussian profile associated with water molecules experiencing stronger $\mathrm{H}$-bonds, W2. Two types of water molecules are present in hybrids stored in closed vials and at room temperature. Concerning silanols groups, isolated and gemini (two $\mathrm{OH}$ on the same $\mathrm{Si}$ atom) are not differentiated and give rise to a single component with a Lorentzian shape.

Other Si-OH groups, all experiencing H-bonds, either mutual or with water molecules, give much broader 
components with a Gaussian shape and a shift toward larger wavelengths values. The proposed quantifications were compared with the fraction in microporous volume as measured by $\mathrm{N}_{2}$ sorption and given in Table 3 in the main text. A larger microporous volume is systematically associated with a larger fraction of isolated and/or gemini silanol groups. A special attention to the location of isolated/gemini groups inside the disordered micropores in silica walls and not inside mesopores or outside silica grains is now thus justified.

Table SI1:Positions, Full-Width at Half Maximum( FWHM) and integrated Relative Intensities of near Infrared signals attributed to water molecules W1 and W2, and to silanol groups : S1) second overtone of silanol bending, poorly bound by $\mathrm{H}$ bonds, $\mathrm{S} 2$ ) second overtone of silanol bending linked by strong $\mathrm{H}$ bonds, S3) second overtone of silanol bending isolated or gemini groups.

\begin{tabular}{|l||l|l|l|l||l|l|l|}
\hline Sample & SILANOL & 1 & 2 & 3 & WATER & W1 & W2 \\
\hline \multirow{2}{*}{ A_C } & Position (nm) & 1458 & 1398 & 1367 & Position (nm) & 1938 & 1897 \\
\cline { 2 - 8 } & $\begin{array}{l}\text { FWHM (nm) } \\
\text { Integrated }\end{array}$ & 237 & 209 & 85 & FWHM (nm) & 235 & 86 \\
\hline \multirow{2}{*}{ B_tensity \% } & 45.9 & 44.1 & 10.0 & $\begin{array}{l}\text { Integrated } \\
\text { intensity \% }\end{array}$ & 55.1 & 44.1 \\
\cline { 2 - 8 } & Position (nm) & 1456 & 1402 & 1367 & Position (nm) & 1936 & 1894 \\
\cline { 2 - 9 } & $\begin{array}{l}\text { FWHM (nm) } \\
\text { Integrated }\end{array}$ & 430 & 232 & 83 & FWHM (nm) & 235 & 86 \\
\hline \multirow{2}{*}{ C_C } & Position (nm) & 1451 & 1400 & 1365 & Position (nm) & 1926 & 1888 \\
\cline { 2 - 8 } & FWHM (nm) & 408 & 129 & 75 & FWHM (nm) & 404 & 84 \\
\cline { 2 - 8 } & $\begin{array}{l}\text { Integrated } \\
\text { intensity \% }\end{array}$ & 61.0 & 17.5 & 21.7 & $\begin{array}{l}\text { Integrated } \\
\text { intensity \% }\end{array}$ & 83.5 & 16.5 \\
\hline
\end{tabular}




\section{Supplementary Information SI5 - $\mathbf{N}_{2}$ sorption main results.}

Results obtained by $\mathrm{N}_{2}$ sorption on calcined silicas have been summarized in Table 3 in main text. The isotherms recorded on silicas submitted to HT are of type IV, as defined in IUPAC. For given precipitation conditions, an applied hydrothermal treatment is associated with a significant change of the hysteresis loop, changing from $\mathrm{H}_{4}$ to $\mathrm{H}_{2}$ or $\mathrm{H}_{1}$ in IUPAC classification. For a $\mathrm{H}_{4}$ hysteresis, parallel absorption and desorption branches, corresponds to uniform mesopores, are observed. $\mathrm{A} \mathrm{H}_{1}$ hysteresis is rather expected with lamellar materials, porous graphite for instance. $\mathrm{H}_{2}$ hysteresis corresponds to more complex porous structures and are generally observed with pore blockings. They are common in cubic silicas containing partially connected mesopores of similar dimension for instance.

The contribution of micropores, as determined qualitatively by the position of the first flat stage of the isotherm (or by the origin of the first straight line that can be obtained on a usual t-plot curve) is particularly high for silica A_C but this silica is not well ordered (as detected by SAXS). Textural properties are modified, as a function of the applied synthesis conditions as illustrated by Figure $15 \mathrm{~A}$ ) $\mathrm{HCl}, 2 \mathrm{~mol}^{\mathrm{L}} \mathrm{L}^{-1}$ B_HT130_C (washing with 3 L of water for $50 \mathrm{~g}$ ) and $\mathrm{HCl} 0.3 \mathrm{~mol} . \mathrm{L}^{-1}$ in C_HT130_C (normal washing $3 \mathrm{~L}$ for $50 \mathrm{~g}$ ) for instance. Textural properties are also altered by washing treatments, see the two other curves on the same A part of Figure 15 they have been obtained with the same powders but after washing with $5 \mathrm{~L}$ of water. The washing in itself is responsible of a strong decrease of porosity.

It is interesting to compare the curves in Figure 15, corresponding to precipitated hybrids to the curves obtained on the evaporated F_U sample washed with 6 L of water and then calcined in air at 130 (a), 350 (b) and $550^{\circ} \mathrm{C}$ (c) - Figure 16 . With this peculiar sample, the influence of the washing treatment is less important and manifested by an independent wave that is observed before the capillary condensation inside the mesopores. This wave intensity is decreased by thermal treatments (compare the curves after calcination at 150 and $\left.550^{\circ} \mathrm{C}\right)$.

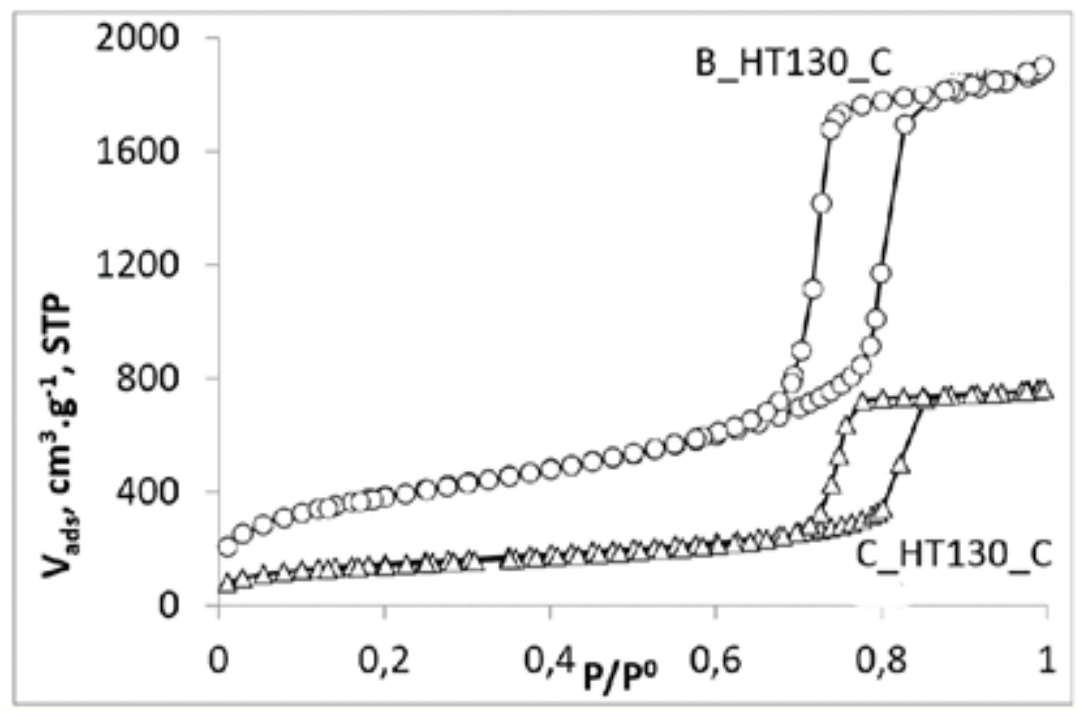


Fig. 15: $\mathrm{N}_{2}$ sorption measurements on two precipitated silica, obtained at the same acidic $\mathrm{pH}(\mathrm{pH}=0)$ uncalcined or submitted to washing treatment with water before calcination, calcination applied then $\left(500^{\circ} \mathrm{C}, 6 \mathrm{~h}\right.$ rate of $5^{\circ} \mathrm{C}$ by min): B_HT130_C sample and C_HT130_C washed with 2 L of distilled water.

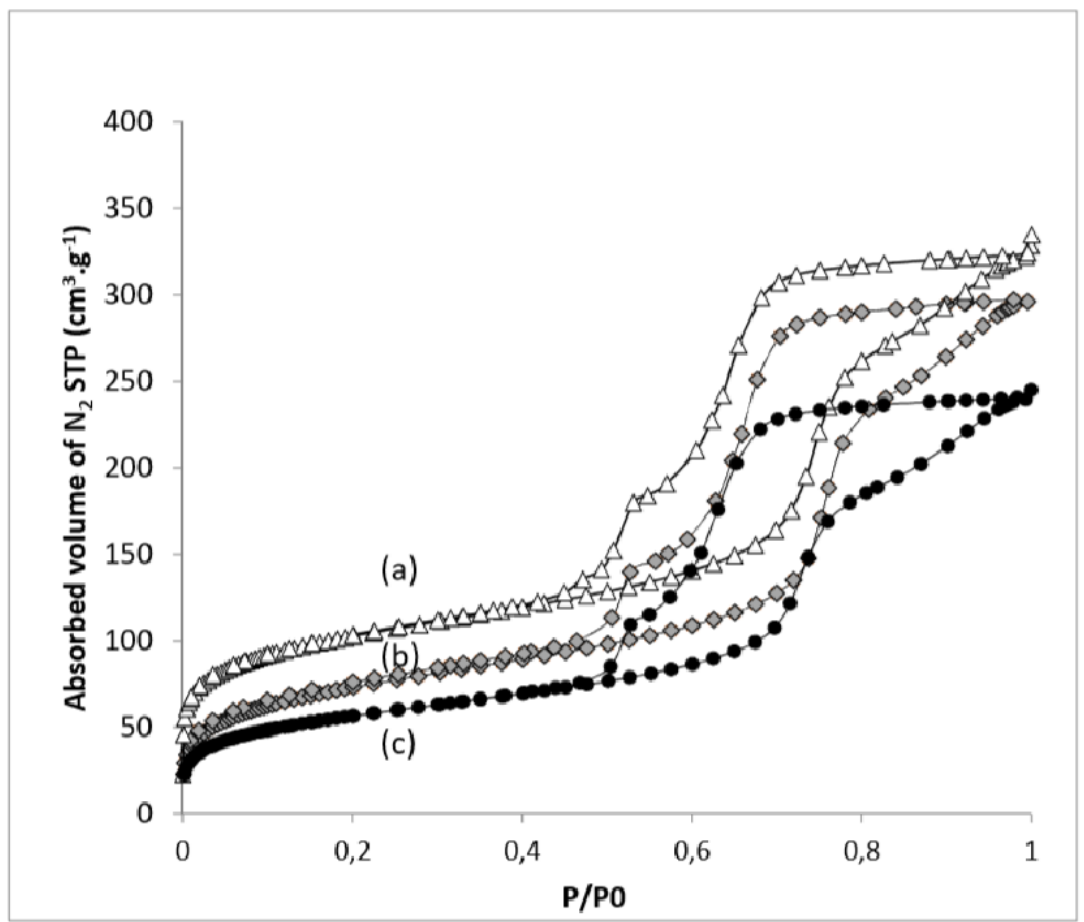

Fig. 16. $\mathrm{N}_{2}$ sorption recorded on the $\mathrm{F}_{-} \mathrm{U}$ sample after washing with $6 \mathrm{~L}$ of water and calcination at several temperatures, a) 130 , b) 350 and c) $550^{\circ} \mathrm{C}$. 


\section{Specific references in Supplementary Information}

[1] Sayari, A.; Han, B.-H.; Yang, Y. (2004) Simple Synthesis Route to Monodispersed SBA-15 Silica Rods. J. Am. Chem. Soc. 126, 44, 14348-14349

[2] Lee, Hyung Ik; Kim Hoe Jin; Stucky, Galen D.; Shi, Yifeng; Pak, Chanho ; Kim, Ji Man (2014) Morphology-selective synthesis of mesoporous SBA-15 particles over micrometer, submicrometer and nanometer scales., J. Mater. Chem. 20, 39, 8483-8487.

[3] Schmidt, P.; Badou, A.; Fröhlich, F. (2011) Detailed FT Near-Infrared Study of the Behaviour of Water and Hydroxyl in Sedimentary Length-Fast Chalcedony, SiO2 upon Heat Treatment. SpectroChim. Acta A, 81, 1, 552-559.

[4] Schmidt, P.; Lauer, C.; Buck, G.; Miller, C.E.; Nickel, K.G. (2017) Detailed Near Infrared Study of the 'Water'-Related Transformations in Silica Upon Heat Treatment. Phys. Chem. Miner., 44, 1, 21-31.

[5] Christy, A. A. (2010) New Insights into the Surface Functionalities and Adsorption Evolution of Water Molecules on Silica Gel Surface: A Study by Second Derivative Near-Infrared Spectroscopy. Vib. Spectrosc., 54, 1, 42-49.

[6] Genkawa, T.; Watari, M.; Nishii, T.; Suzuki, M.; Ozaki, Y. (2013) Two-Dimensional Heterospectral Correlation Analysis of Water and Liquid Oleic Acid using an Online Near Infrared/Mid-Infrared Dual-Region Spectrometer. Appl. Spectrosc., 67, 7, 724-730.

[7] Langer K, Flörke OW (1974) Near infrared absorption spectra (4000-9000 $\mathrm{cm}^{-1}$ ) of opals and the role of "water" in these $\mathrm{SiO} 2 \cdot \mathrm{n} \mathrm{H} 2 \mathrm{O}$ minerals. Fortschr. Mineral, 53, 17-51.

[8] Kronenberg, A. K. (1994) Hydrogen Speciation and Chemical Weakening of Quartz Heaney, P. J., Prewitt, C. T., Gibbs, G.V. Eds. Silica: physical behaviour, geochemistry and Materials Applications. Review in Mineralogy 29. Mineralogical Society of America, Washington, 123176. 
